\title{
FORGOTTEN MEMORIES: \\ THE NOTION OF SACRUM IN ARTISTIC EXPRESSION
}

by

RADEK PACANOWSKI

A THESIS PROJECT DOCUMENTATION PRESENTED TO

RYERSON UNIVERSITY AND YORK UNIVERSITY

IN PARTIAL FULFILLMENT OF THE MASTER OF ARTS

IN THE JOINT GRADUATE PROGRAM IN COMMUNICATION AND CULTURE.

Prepared for:

PROFESSOR DON SNYDER, RYERSON UNIVERSITY

PROFESSOR JOHN VAINSTEIN, YORK UNIVERSITY

TORONTO, ONTARIO, CANADA, 2009 


\section{Abstract}

This paper is a critical examination of the artistic process undertaken to complete a mixed media art installation, exploring the concept of "sacrum" as the nucleus of the peasant culture of XIX century Poland. As demonstrated by the prevalence of sacred inclinations embedded in the moral consciousness of Polish peasant history, sacrum is the innate orientation towards realities that transcend time and matter - the active and passive reflection of that which lies outside the realm of human sensory experience. At its core, this project explores sacred elements embedded in Polish culture - these elements are not merely reflected upon, but are also reacted to and acted upon by the artist, thus revealing the forgotten sacredness of the most mundane objects and practices of human life. As such, this creative process functions as a research tool, which, by using interdisciplinary illuminations, now acts as a stimulus for the creation of new knowledge. Utilizing the notion of praxis, this project determines whether artistic expression facilitates the communication and sharing of undiluted knowledge. The ultimate aim of this endeavour is to understand the extent to which the artistic process is capable of sustaining the pure essence of expression, and of mediating the transcendent elements inherent in human culture.

The approach taken is based on the richness of signals emanating from the artist's own personal history. It includes not only that which is utterly personal, but also that which is culturally determined, offering insight into the various social forces shaping the content of one's own self-identity. The process of tracing the lineage of a personal story is the chosen means used to deconstruct the complexity of cultural tectonics. Through a series of ritualistic actions, embedded with both personal and cultural significance, a transformation takes place, in that, the resulting disarray of energies, now freed from the skeletal structure of self-reality, reveal a sharper, more enlightened view of the spirit that permeates the artist's enveloping culture.

The conclusions derived, highlight the inherent complexity of the artistic cycle and the various ways in which the intended message is distorted and/or misinterpreted. However, as suggested by the study's findings, this unavoidable, resulting distortion need not detract in any way from the inherent value of artistic expression and the artistic process. The creative journey taken was truly successful in the realization of a fuller, broader understanding of personal identity within a larger cultural, historical context. In addition, the commitment to praxis, as opposed to passive reflection, successfully revealed evidence of sacrum's inherent, interwoven existence within a greater personal and cultural ontology. 


\section{Acknowledgements}

Many people supported this project and contributed to its final manifestation. I would like to take this opportunity to acknowledge them.

I am indebted to my advisors Don Snyder and John Vainstein as well as the chair of my defense, Mirella Cirfi Walton, for their wisdom, inspiration and mentorship. I am immensely grateful to Ewa Bielec, Jacek Jackowski, Jo Ann Mackie and Mondek Szeliga for their collaboration and assistance. I sincerely thank the management of University of Guelph-Humber: John Walsh and Gabrielle Bernardi-Dengo for the generous support of this project. I also want to extend sincere thanks to Shirley Camia, Rick Davis, Patrycja Hurek, Olga Naumenko, Mathan Shan and Rick Thomson for all their valuable suggestions, constructive advice and moral support. I would like to express my deep appreciation to Krystyna and Peter Klimek for their immense help with this project, and the spiritual support they have been providing me.

My special gratitude goes to my family: my parents and my sister, for their unconditional love, support, honesty and patience. And to my grandmothers whose stories inspired this project.

Thanks to all. 


\section{Table of Contents}

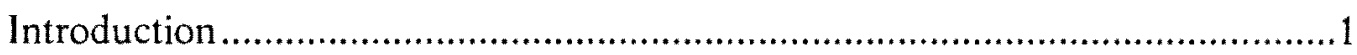

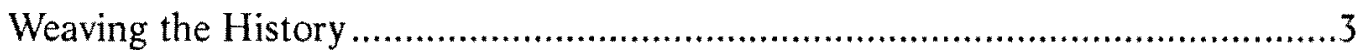

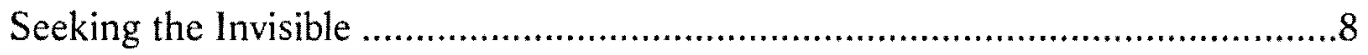

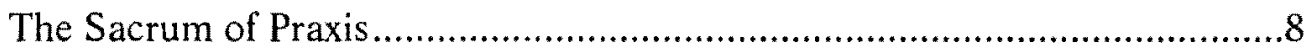

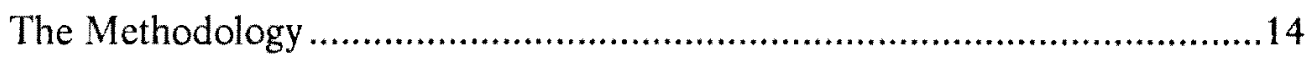

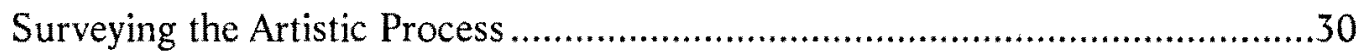

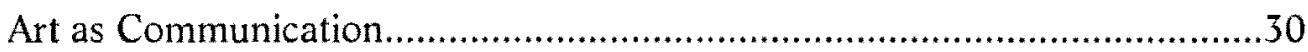

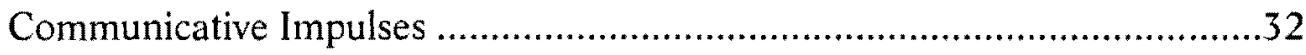

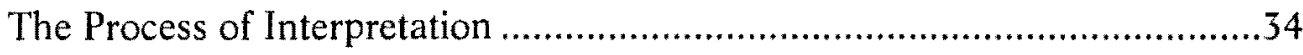

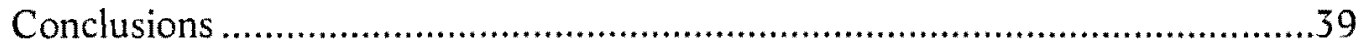

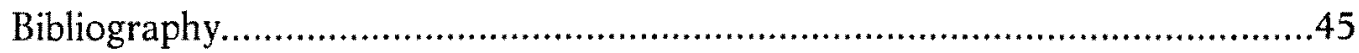


Only a feeble light glimmers like a tiny star in a vast gulf of

darkness. This feeble light is but a presentiment, and the soul,

when it sees it, trembles in doubt whether the light is not a dream, and the gulf of darkness reality.

Wassily Kandinsky from "Concerning The Spiritual In Art"

\section{Introduction}

The regenerative and harmonizing appeal of artistic work finds its purest

expression through the sensibility of its creator and the innocent mind of its viewer. The passion to create is conveyed in the nced to express the many intricate elements of an enveloping reality, to give shape to the inborn desire to decipher the indescribable facets of life, to speak of the subliminal and acquaint oneself with the subconscious. The kernel of artistic expression can be argued to lie within the primal need to crystallize the many intricate manifestations of one's consciousness. Artistic expression further extends its regenerative and harmonizing embrace in the attempt to rationalize the multilayered essence of our being. The notion of recollection becomes a way of contemplating the nature of reality, setting new grounds for a meditative connection with the environment encompassing one's emotional self. This unique form of multi-sensory narrative carries an immense emotional load: capable of directing the inner voice of the narrator and potentially providing a means of personal liberation.

The fundamentally raw human desire to communicate what seems implicitly 
inexpressible often leads to artistic works largely personal in nature, thus limiting their ability to evoke intended emotional responses in the audience. The poor articulation of the embedded emotional undertones can further instigate often unintended interpretative retaliation, muddling the artistic work's silently established authentic aim. Although the authenticity of the artist's communicated dogmas cannot become the main determinant within the subjective realm of human reason, one can attempt to trace the divergent forces affecting the lineage of the artistic process. It is this endeavour which can extract useful conclusions embedded within the mechanisms of the artistic cycle, thus illuminating the depth of the conveyed meaning: its authentic purity. It is not the morality of the message that is being questioned here, but rather the array of forces sculpting the message's content as it emanates through the cycles of artistic processes. The surveyed level of purity in artistic expression therefore pertains to the articulation of the communicated message, and its survival in the many overlays of socio-political undercurrents fuelling its propagation.

The thesis of this project is established through the methodology of artistic practice concerned with the process of discovering and conveying highly experiential insights. In its core, the project described here deals with sacred elements embedded in cultural history that are not merely reflected upon, but are rather reacted to, thus further reiterating the forgotten sacred significance in the most mundane objects and practices of human life. As such, the undertaken artistic process itself also becomes a research tool, which by using the illuminations of such doctrines as comparative history, aesthetics, ethnography among many others, now acts as the stimulus for the formation of new knowledge. This approach echoes the work of such educators as Hernandez-Albujar, who illustrates the reciprocal 
effects of integrating experimental visual art into the sociological discourse ("The Symbolism of Video: Exploring Migrant Mothers' Experiences"), or Visual Studies scholar David Joselit, who, using examples of work by artist Peter Campus, demonstrates how the notions of spectatorship and culturally mediated self-identity are anatomized in video art to create the effect of an instantaneous moment of reflection in the viewer (Joselit 454). As such, it is this project's aim to identify praxis as a form of active meditation (Welch 63) in the artistic process, functioning as a mechanism of discovery in the attempt to unveil hidden traces of sacredness.

\section{Weaving the History}

The year 2009 marked my senior semester in the Communication and Culture program and coincided with my sixteenth year - or half of my life - in North America, after emigrating from Poland. It was in 1993 when I was thrown into a culture saturated with varying social, religious and political ideologies. Multiculturalism was an exotic phenomenon at first, and soon took a strong grasp on my previously established homogenous identity. It was an overwhelming yet exciting adventure, which propelled me to experience a vast array of varying philosophies of life. This allowed my previously instilled strong interest in human interaction through communication to acquire a new dimension, where I cherished the multiplicity of approaches manifested within the dynamic flux of cultural values.

Several years ago, I accidently stumbled upon a journal paper written by UCLA 
professor Michael Owen lones entitled 'Tradition' in Identity Discourses and an Individual's

Symbolic Construction of Self. In this paper, Jones focuses on the notion of tradition and its use in the construction of self-identity by presenting his research on the life of Gary Robertson: a unique individual of Polish and Ukrainian descent, whose abusive childhood experiences steered him into a reclusive life on a farm east of Winnipeg, Manitoba. The particularly fascinating aspect of Gary Robertson's life was the development and use of expressive forms of identity formation, or what Jones called "identity discourses" (120). In this process, Robertson's identity was consciously shaped by a dynamic praxis of interaction and self-reflection, actualized throughout a 20 -year construction of his farm home built to resemble an Orthodox chapel (Figure 1). Gary Robertson's poor physical and mental

Figure 1: Gary Robettson in front of his house in Whitemouth River, Manitoba.

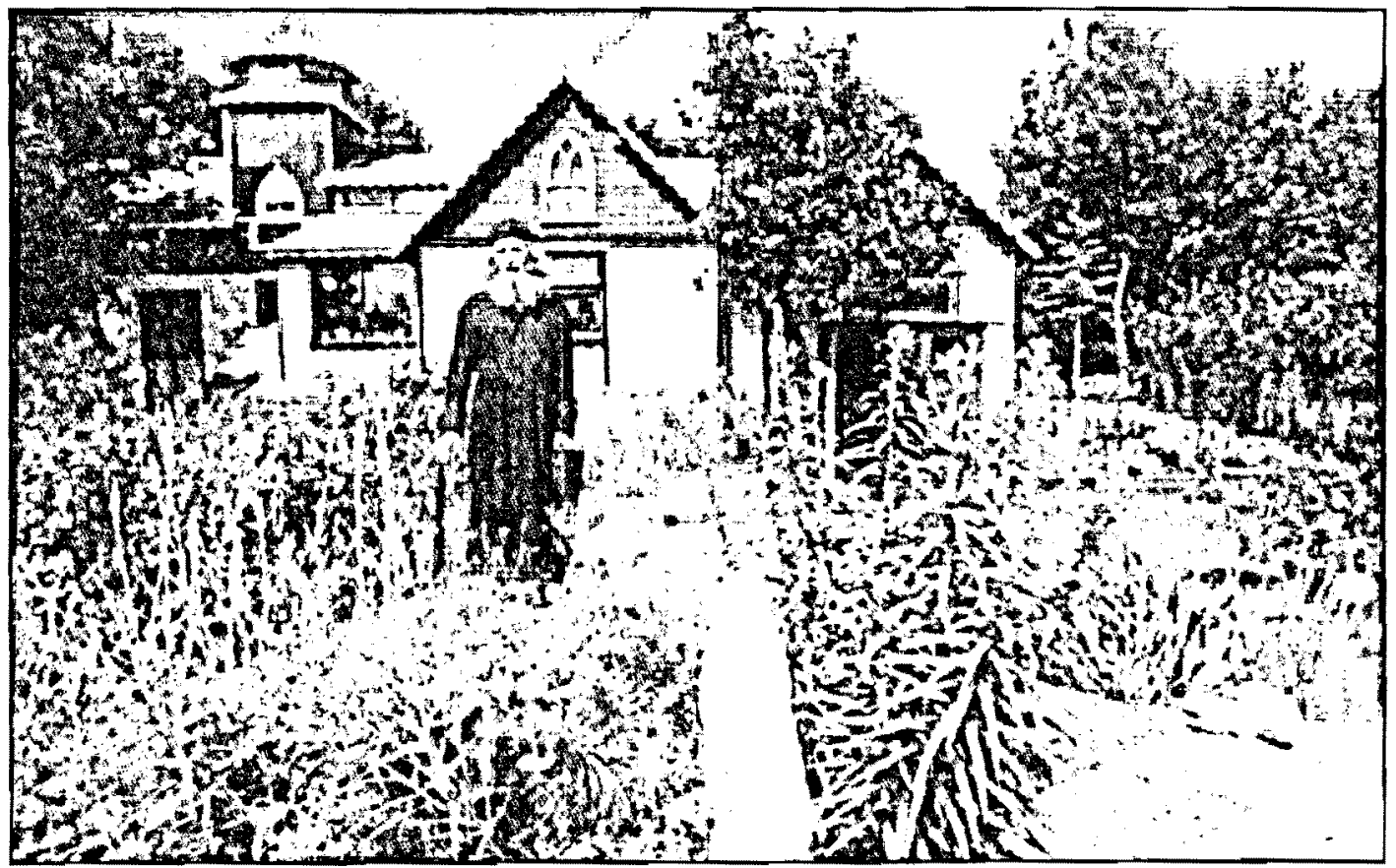

Soure: Jones, Michael Onen. "Tradition in ldentity Discourses and an Individwals Symbolic Corwtruction of Salf." Westent Folklore 59.2 (2000): 122.

health, intertwined with a difficult personal past, forced him to build an environment and a 
lifestyle based on self-created identity - further expressed through diverse forms of creativity, such as scrapbooks and traditional icon paintings, in the attempt to resolve issues originating in his childhood (Jones 131). Jones' account of Robertson's life is a fascinating inquiry into some of the ways in which we strive to find the deeper meaning of our existence and to understand the forces propelling our cultural identity. It was the way Robertson chose to describe the house he built, however, that especially captivated my interest:

This is not just a house or a home, this is my own exterior from inside, my soul's exteriorizing with the building. The fact that it's wood, it's logs-it's natural. Touching. So I guess when I'm sitting in the room everything is touching me, because in a sense everything in it is from within. (qtd. in Jones 123)

These profoundly raw and powerful words provoked an immense resonance of emotional memories in my consciousness, and I began to reflect on the way my own identity had been shaped by the divergent cultural forces of Eastern Europe and North America. This personal recollection soon crystallized the need to understand the many intricacies shaping my creative motivations. What facets of my modern consciousness were inherited from the contrasting cultures of Eastern Europe and North America? To what extent was my creative potential determined by the cultural tensions shaping my dialectic heritage? These questions were not important to me solely on a personal level, but more so because they required taking a holistic approach with the intention of better understanding the very myths fuelling my cultural identity.

I began my research around the topic of artistic expression in the context of 
tradition, myth and ritual, which I saw as cohesive to my cultural roots. I was introduced to the writings of Suzi Gablik, whose views of the post-modern art scene were often bleak, but aptly redeemed by the conviction that the reintroduction of old ideals and art products containing the most personal depth and moral values can divert us from falling into the abyss of nothingness. This proposition is also reinforced by mythologist Joseph Campbell, who describes Carl Jung's views on realigning oneself with the "greater horizon of our own deeper and wiser, inward self" (Campbell, "Myths to Live By" 15). Jung argues that human preoccupation with the demands of the physical world has diminished our connection with the inner psyche and its inward forces. As such, he promotes his conviction that the study of myth aids in maintaining a delicate balance between the two realms by means of "a dialogue by way of symbolic forms put forth from the unconscious mind and recognized by the conscious in continuous interaction" (Campbell, "Myths to Live By"15). The depiction of myths as clues to the spiritual potentialities of the human life (Campbell, "Power of Myth" 5), allowed me to make a brief departure to Benjamin's notion of the loss of art's aura. In his view, aura is perceived as a transcendent element of an original artwork; it is authentic, and able to evoke emotions at the highest level. As reproducibility becomes an inescapable part of today's reality, so does the withering of art's aura, argues Benjamin ("The Work of Art in the Age..." 21). This translates into a question of art as a way of manifesting the cultural truths of tradition: perhaps the diminishing line between art and cultural objects expunged of much meaning has now become more pronounced and thus further denigrates art's status as a conveyor of Truth?

In his address to the American Folklore Society, professor Wilhelm Nicolaisen 
observes that tradition "[...] has been equated with communal creation and re-creation in the atmosphere of anonymity, and the emphasis has been on the transmission of knowledge, customs, and beliefs through such anonymous channels in an almost mystical fashion" (qtd. in Bronner 47:85). The prevalence of tradition and its manifestation in folk life (Benet 15) has established itself as one of the core elements in sustaining the Polish culture throughout its turbulent history. Growing up in a small town surrounded by farm fields, I spent much of my youth observing and participating in the lives of farm families, whose close connection with the land was not only essential to their survival, but was also the way of life. The many intricacies of traditional values were so closely intertwined in most of the mundane daily activities that I observed, their importance almost seemed at risk of conscious neglect. It was the culture's symbiotic relationship between the sacred and the secular, however, that prevented such neglect from occurring. This dichotomy is often depicted in the anthropological research of Sula Benet, Ludwik Stomma and Roch Sulima to name a few, who observe the near practical approach of the Polish peasant culture to the sacred: "[t]hey are concerned with the Deity and the Saints as living beings who can help or harm, not as the embodiment of abstract principles. [...] The peasant is a realist in a world where saints, ghosts and black magic have as much reality as the barley in his field and the cow in his stable" (Benet 25). The divine wisdom is seen here as a practical and earthly incarnation of the sacred with its essence grounded in practical tasks. The culture I grew up in did not simply teach me to react to transcendent notions, but rather, incorporate them as the founding blocks of my being.

This realization became the crucial point in the development of my thesis. It is here 
that $I$ realized that the intimate connection between human existence and the numinous forces I grew up with was being saturated by repetitive, mundane acts I so often witnessed and participated in as a child. The metaphorical implication of the notion of praxis became clear to me: I wanted to translate this newly acquired understanding into an artistic process. Furthermore, I wanted to understand if this process could be regarded as a conveyor and enabler of knowledge, thus becoming implicated in a larger educative context. Placing special emphasis on praxis would allow me to strengthen my connection with the larger social order (Bronner, "Art, Performance, and Praxis" 94) thus situating my identity in the context of community. I devoted the next several months meditating on the process of artistic expression along with the potential mutability of its intended message. My intention throughout this process was to understand the extent to which the artistic process is able to sustain the pure essence of expression, and result in a gradual induction of awareness of the non-physical aspect resonating in the artistic work.

\section{Seeking the Invisible}

\section{The Sacrum of Praxis}

The imprint of meaninglessness (Gablik 85) formulates its strong presence in today's pluralistic era (Ibid. 83), propelling the pursuit to purify the emanating messages of artistic expression and strengthen its fragile fabric. "However fragmentary its condition, any work of art is actually a portion of arrested happening, or an emanation of past time," 
posits Kubler (17) as he meditates on the historical significance of artistic expression, and notes the paramount essence of art as the signalling beacon for the future. It is this stability of the message (Ibid. 19) that charges the artist with the responsibility to embrace and convey the authentic voice of the natural order (Scruton 7). The seeds of the utopian concept of absolute freedom have sprouted into a vast plane of "increasing randomness and loss of direction" (Gablik 86), and are now disrupting our pursuit for the Hegelian truth. The only truth pluralism allows, posits Gablik (87), is that it is absolutely true that there is no such thing as absolute truth. What seems to be suggested here is very much universal in scope: the articulation is that the contemporary culture has lost its interest in pursuing higher meaning. The lack of consistent knowledge about reality becomes problematic as we now sever our connection with life's moral centre. Gablik comments: "nearly all art today is the product of energies freed from the direct social purpose or obligation," (84) and thus, the notion of value-blind society is being instilled here, a society that is no longer able to realize its potential, no longer longing for the inward journey of self-maturation. The methodological propagation of mass-mediated narratives gives birth to rewritten myths and proclaims new societal dreams and ideals. The abdication of these new truths from any form of constancy of tradition, however, gives little opportunity for the development of one's holistic awareness and connection with the universal consciousness. The diminishing importance of past traditions and the growing sovereignty of self-identity (Scruton 115) further disorient one's motivation for personal growth, and strip away any revelations of human wisdom (Campbell). This leads to a critical enquiry into the forces needed to aid the re-negotiation and redefinition of the culture's core 
constructs. It is a reciprocal attempt, rooted in the need to re-establish self-connectedness with the larger realm defining one's place and purpose.

One possible approach suggested here is to focus on the richness of signals emitting from the artist's personal history and the various cultural subtleties caught in its fabric. Stemming from fragmentary manifestations of moments shaped by structures of time, such enquiry embodies not only that which is utterly personal, but also strives to offer an important insight into the various social forces shaping the recollection of the artist's personal history. Such process of tracing the lineage of the personal story is designed to become a way of deconstructing the rich complexity of cultural constitutes. It is a transformation through meditation - an attempt to both comprehend the disarray of energies freed from the skeletal structure of self-reality, and to present a sharper, more enlightened view of the spirit that surrounds the artist's enveloping culture. Without a doubt this is a risky adventure. Such illumination carries the risk of evolving into a selfcentred exploration with an insignificant recompense for an outside viewer of the work. This process must rely on maintaining a delicate balance between the creator's instigated feed of experiential energy and the resulting array of possible interpretations. It is only then that this delicate circuit will provide a means of evaluating the communicative signals between the creator and the viewer of the work. In the context of the work, this process provides a way to escape the past and arrive at what Sontag (13) calls transparence: experiencing the luminousness of the thing in itself.

The practical approach undertaken in this thesis project works with the argument that many mundane products of the Eastern European culture assume elements of sacred 
significance, thus indicating the fundamental need to understand and manifest the significance of human life. The need to contemplate one's humanness seems to be present in all evolutionary stages of man's creative expression. From the primitive cave paintings and their celebration of the mysteries of life, to contemporary films of Tarkovsky, Malick or Zvyagintsev, one witnesses the common thread in the attempt to locate the "centering point for meditation and contemplation that leads towards the possibility of a spiritual encounter that is fundamentally grounded in an aesthetic experience" (ApostolosCappadona xiii). But these notions have succumbed to what Eliade calls involuntary camouflage ("Symbolism, the Sacred, \& the Arts" 82), their manifestations forgotten in the modern language of expression, yet continuously sending weak signals for future rediscovery of their inner meaning in "the materialized fields of energy and matter" (Beuys qtd. in "Reclaiming the Spiritual in Art" 63).

Such impulses are the base interest of this thesis, which considers the notion of sacrum as the core interest in the endeavour to free oneself "of the 'surface' of things and to penetrate into matter in order to lay bare its ultimate structures" (Eliade, "Symbolism, the Sacred, \& the Arts" 83 ). First introduced in the 1960 s by Polish art critic Janusz Bogucki, the term sacrum embraced "an attempt at rediscovering the relation between the sacrum of art and the primal sacrum, manifested in reflection on the timeless and nonmaterial meaning of human existence" (Gralinska-Toborek 1). Although initially deeply rooted in the Catholic Church's fundamental position in Poland's intertwined religious and political spheres of the 1980 s, the significance of the religious aspect of sacrum in the arts has largely diminished. "Religious iconography and activities associated with religious 
practices are treated as quotations, pretext or provocation, and thus no longer fulfil their basic function," argues Gralinska-Toborek (7), pointing out the loss of the "sacral or transcendental dimension" (7) of contemporary art. This separation between the works of creative expression and the element of the sacred, however, does not necessarily suggest a prevailing impartiality to spiritual attainment. On the contrary, some notice a growing trend among the artistic spheres to reclaim art's meaning-giving dimension (Gablik, Perlmutter, Koppman, Shantz and others), to again reposition the role of an artist as one that reflects "the conscience of the World" (Sulima 123). This thesis works with the argument that sacrum permits its exploration to take place apart from the phenomenology of religion, while still maintaining the possibility of encompassing varying levels of sensuous experience depicted in one's awareness in the "manifestation of something of a wholly different order, a reality that does not belong to our world, in objects that are an integral part of our natural 'profane' world" (Eliade, "The Sacred and the Profane" 11). Transcending the deliberations of the religious discourse, the position of an artist as the modern conveyor of myth (frequently emphasized in Joseph Campbell's work) is assumed here: one who unconsciously strives to depict the granularity of sacrum and express its revelations.

The premise of the project concerns the Polish peasant culture of the XIX century and is based on the proposition that sacrum is fundamentally positioned within this culture's core identity, manifested through daily mundane activities. The central positioning of sacrum draws its roots from the Christian tradition and is unravelled through what the Polish historian and anthropologist Roch Sulima calls kod sakralny (51), 
or the "sacral code." The manifestations of sacrum's indicators in the peasant culture exist on multiple systematic levels, which — as Sulima argues — can be deciphered with the use of kod sakralny and become the source for the formulation of knowledge about this culture. The resonant positioning of sacrum, therefore, becomes the core construct, not only in the formal religious aspect, but more interestingly, in the mythical dimension. In this case, a multitude of seemingly mundane everyday activities further propagates the subtle elements of sacred significance. This saturation with sacrum's reverberation hence transcends the ideology of religion, and becomes the very essence of one's cultural identity.

One of the examples of such ritualistic tasks are the songs performed during harvest activities, as they illustrate the intrinsic quality of sacrum's positioning in the peasant culture. Harvest songs become clear indicators of sacrum's resonance, as they imply a ritualistic, hence sacred approach to life. Polish ethnomusicologist Anna Czekanowska notes such impulses of sacredness in her study of Polish harvest songs, and characterizes them as a "highly specialized genre of folk music, related to certain activities but primarily with a magical function" (Ling 36). The uniqueness of harvest songs lies in their "close connection with ritual" (Czekanowska 24), externalized in the context of communal activities and performances. With their underlying structure built upon "circling movements and repetitions of short phrases and formulae" (Czekanowska 25), the ritualistic character of harvest songs strongly alludes to the notion of trance. Becker defines trance as a "state of mind characterized by intense focus, the loss of the strong sense of self and access to types of knowledge inaccessible in non-trance states" ("Music and Trance" 41). This method of practising "being-in-the-world" (Becker 42) exists in a 
direct link with this project's aim to explore the means of intensifying otherwise undetectable traces of transcendental elements. Especially interesting is the noetic quality of trance states, argued by Becker as having the capacity of allowing the participant to connect to "a special type of knowledge [...] accompanied by a sense of absolute certainty concerning that knowledge" (46). This new awareness attributed to the process of creation and participation in an artistic experience becomes a symbolic expression of this project's theoretical grounding. Praxis, in this case, becomes an expression of personal engagement in the act of creation, translating the past manifestations of tradition into a contemporary artistic process, where the act of expression becomes a sacred commentary in its own right.

\section{The Methodology}

"Forgotten Memories" is a mixed media installation comprised of two hand-built wooden structures inspired by żurawie studzienne: traditional Eastern European wooden crane wells, illustrated in Figure 2 \& Figure 4. The wooden wells were often built using easily found wooden logs, varying in shape and size. The erected wooden well would become a prominent figure in the backyard of a farm, yet its intrinsically natural construction would rarely place it out of context with the environment. The art installation in this thesis project follows the same traditional methodology of repurposing natural materials: each water well structure is built from weathered wooden logs and reinforced 


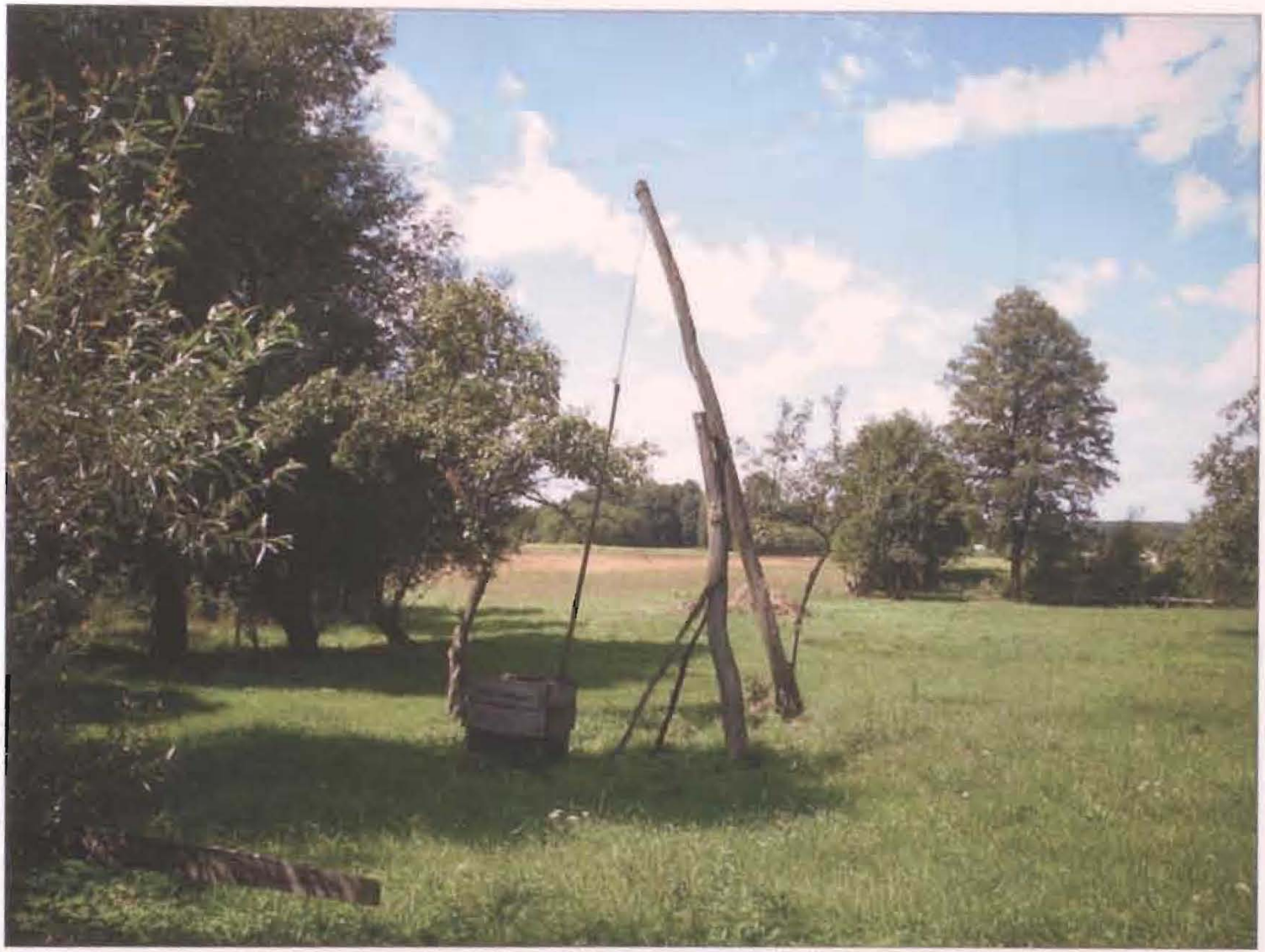

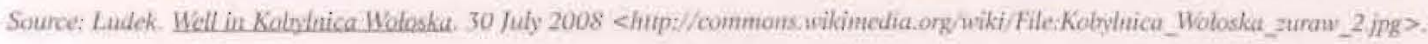

with straw rope. Its auxiliary elements such as the metal handles and chains are derived from found, donated or otherwise heavily used objects. The initial conceptual sketch of the wooden well is presented in Figure 3 and illustrates the primary parts of the structure. A bucket suspended from one end of the well's arm is tied with the use of straw rope, which is then connected to a wooden handle and an old rusted chain connecting the bucket to the rest of the structure. The crane's arm is balanced with a rock attached to the opposite end. The arm of the well is attached to the base, and although it normally uses the lever principle 


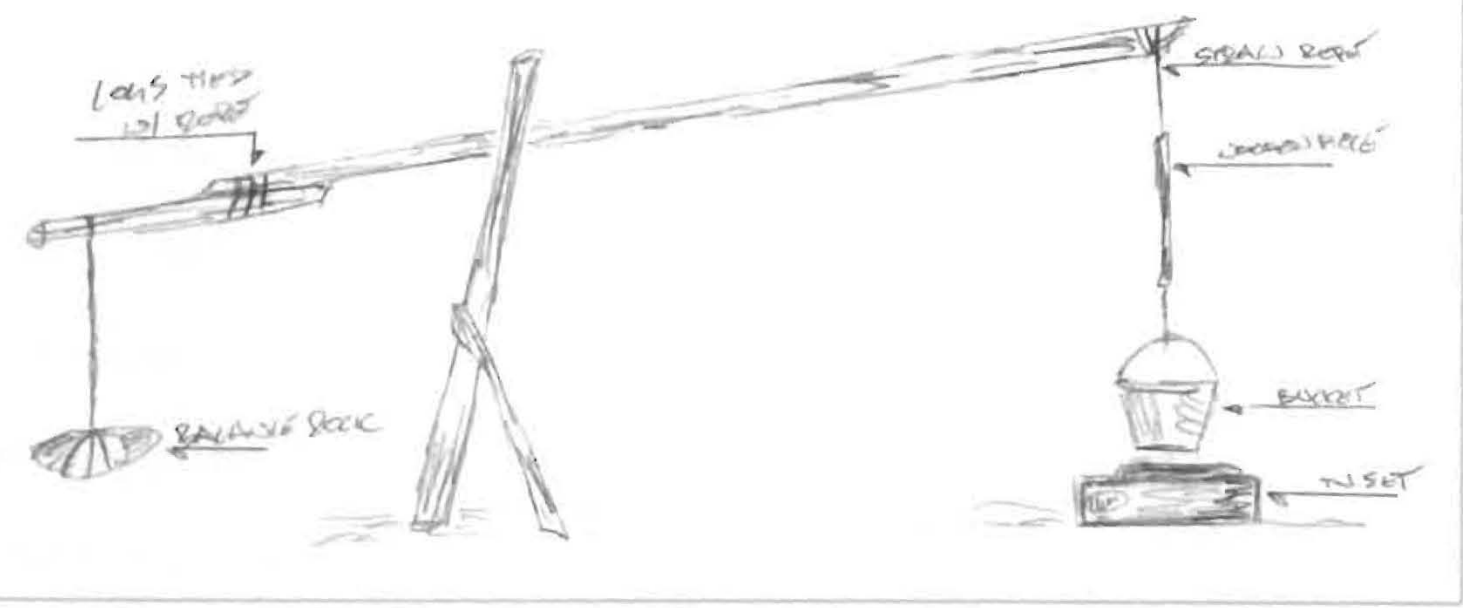

to allow the bucket to be lowered down the well to draw water, it is permanently attached to the base in this particular art installation. Each individual part of the crane water well in this project is attached with the use of straw rope. The base of each structure consists of three wooden legs, tied with rope to alleviate the need for additional support of the structure, and to maintain its visual simplicity.

The prominence of crane water wells is difficult to ignore when witnessed in real life. These simple, yet dominant objects carry a certain degree of animistic presence. Weathered by natural elements, their saturation with history is easily experienced upon physical contact with the structure. It is through this act that I believe one experiences a certain visceral connection with the natural environment which these man-made objects occupy. One of the most interesting contemporary observations made about these structures is the abrupt contrast they convey: one assumes their historical placement, and 
yet, acknowledges their still

persistent practicality. Examples of

such contrasting forces in Polish

culture were highly prevalent

during my childhord, but it was

only after a long absence from my

home country that I was finally

able to fully notice and

comprehend them. A horse-pulled

carriage commonly seen on public

roads, even in the 1990s (Figure

5), not only conveys the economic

disparity at the time the

photograph was taken, but more so
Figure 4: Wooden crane well in the Podlasie region. ca. 1915. From personal family archines of Ewa Bielec. Used with permission.

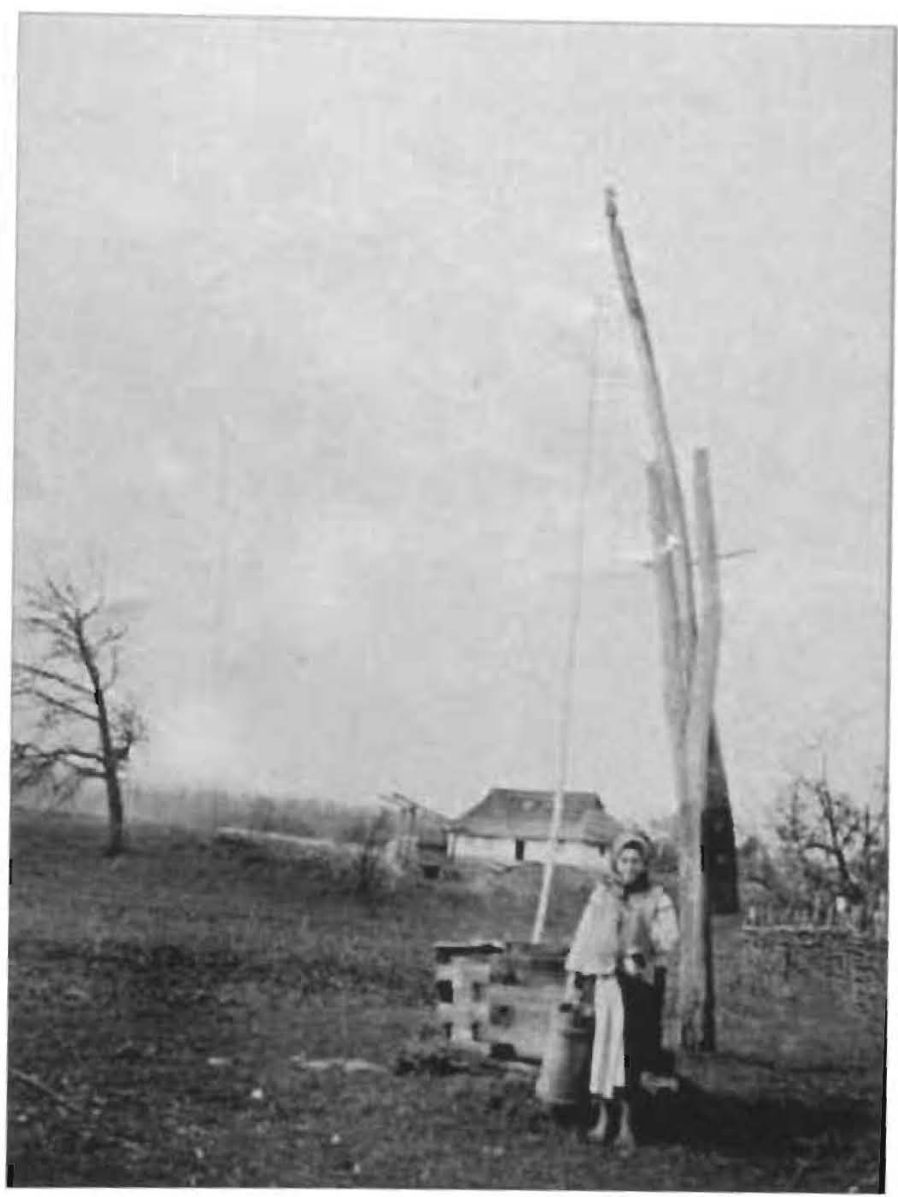

displays the stubborn reliance on ritualistic facets of the culture. Metaphorically, such stubbornness manifests itself as celebratory in the unconscious manifestation of the sanctity of tradition, further fulfilling the acute observations made by anthropologists Ludwik Stomma and Sula Benet. It was these and similar recollections that grounded my conviction to work on my art installation with only found, donated or heavily used natural 


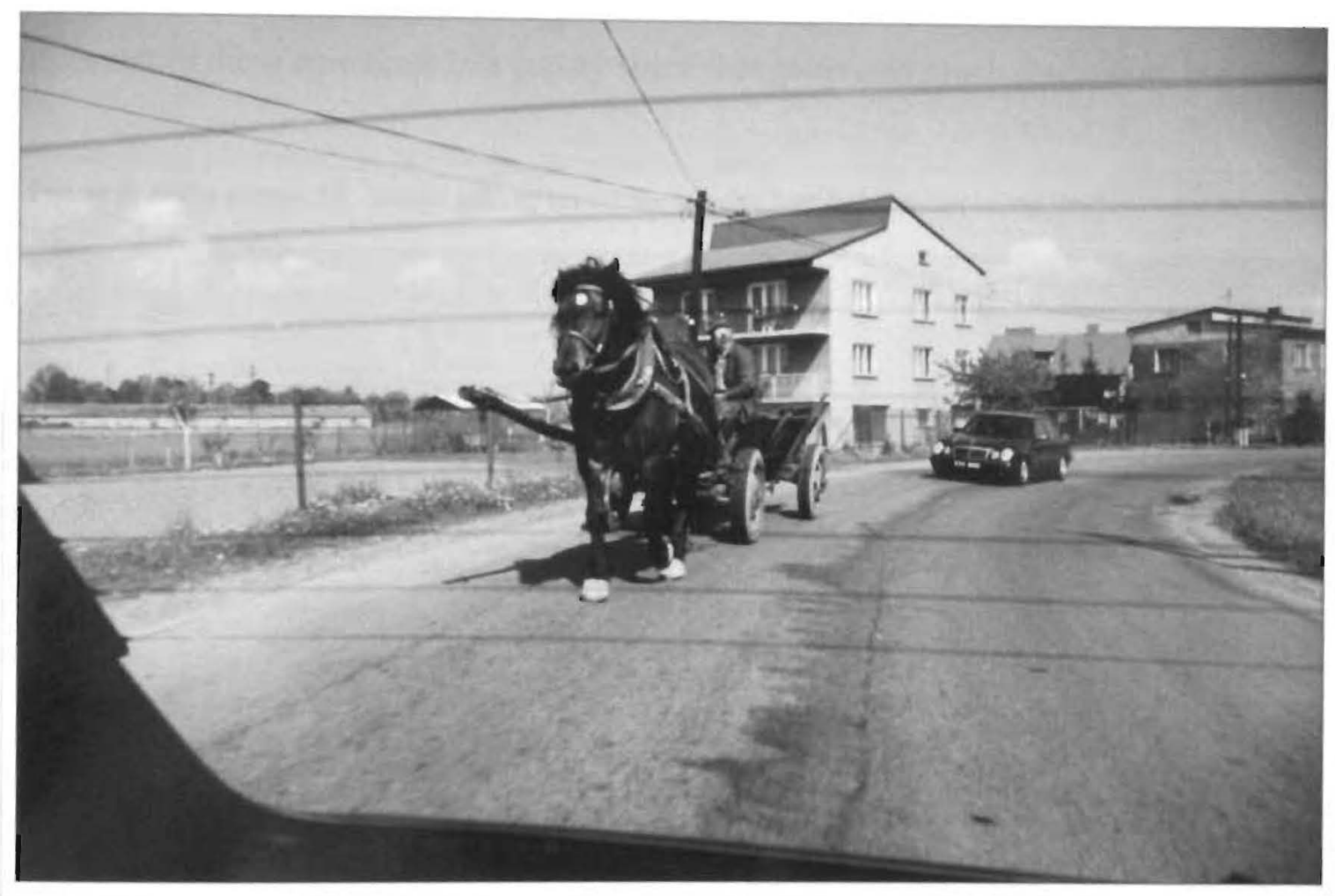

materials - objects that emanated a sense of history. This decision, I felt, would diminish the chances of sanitizing the energy of the installation, and help to preserve the delicate historical abrasions that I was trying to convey.

The involvement of my close family members in the discussion about the premise of this project resulted in immense amounts of helpful stories, photographs, books and people I was urged to talk to. I was invited to visit a Polish farm located near Orangeville, Ontario, where one of the farmers took serious interest in helping me locate some of the materials needed for the construction of the wells (Figure 6). His enthusiasm was highly reminiscent of my childhood interactions with other farmers, whose nonchalant eagerness always manifested an almost silent obligation to offer help. The most difficult aspect of this phase 
was my attempt to verbalize the motivations behind the project, and why I was building two wooden wells that would not even be used to draw water! Interestingly, it was not the placement of these structures in a gallery space that generated much discussion, but the

Figure 6: Polish farmer Mr. Szeliga helping secure the wooden logs for transport to my studio.
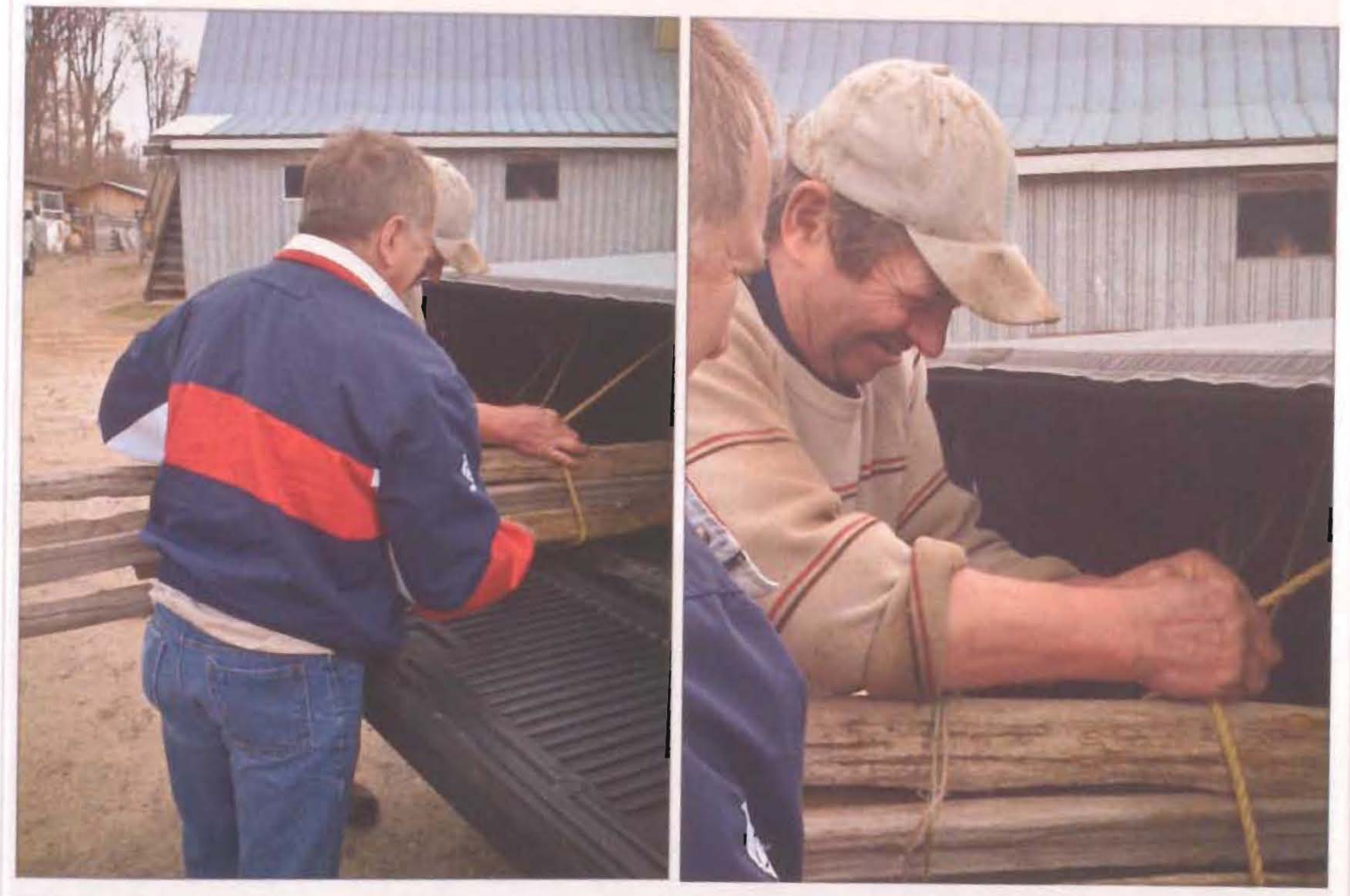

omission of the element of water. I took these concerns seriously as I was starting to feel the resonant significance of the symbolism embedded in this project. Water is most universally formulated as the symbol of a life-giving force. It becomes a vehicle of cleansing and regeneration (Chevalier and Gheerbrant 1081), and is seen as the vehicle of purification of one's being. In the Christian tradition, water is the symbol of "the spiritual life and of the Spirit which God offered and which mankind often refused" (Chevalier and Gheerbrant 1084). In Polish peasant culture, water often acquires healing properties and 
thus protects those bathing in it from illness (Bennet 55). The most interesting facet of water's symbolic meaning is its "intuitive wisdom" (Cirlot 365) and thus the means of using old tools and methods to prepare food for the farm animals.

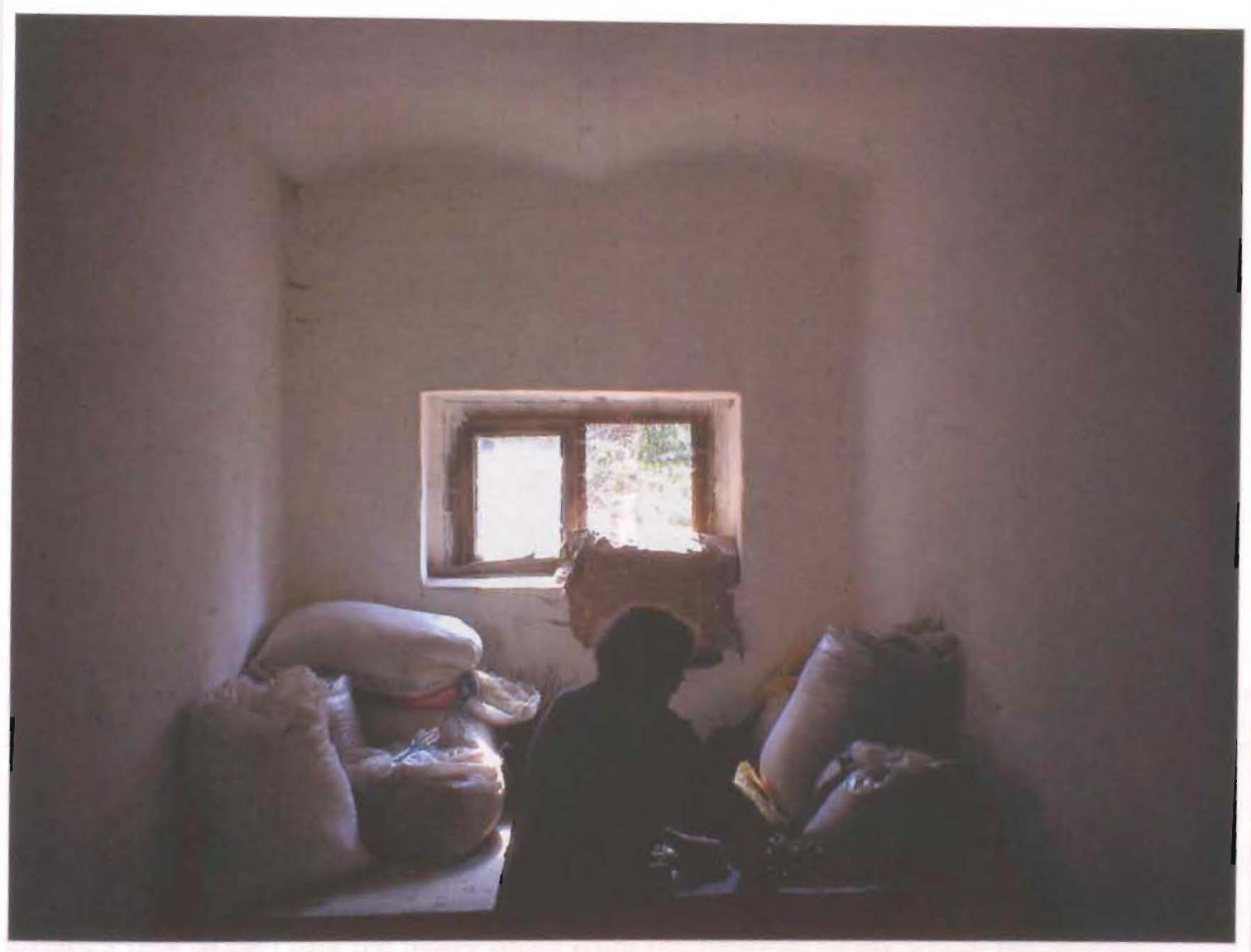

transcending the limits of human understanding to realign with the higher knowledge. Carl Jung's suggestion of water as the symbol for the unconscious mind (Welch 60) should be noted, implying the symbolic depiction of the need to express concepts impossible to clearly define or comprehend (Jung 4). Water's baptismal properties enable the cleansing of one's being, thus preparing for the rites of passage in the evolution of one's self-understanding, alluding to the works of Campbell, Jung and Eliade, among others. I decided to connect 
these descriptions to the project, by introducing a small television set to the installation space, wired to display soundless images of water. I saw this act as a way of drawing special attention to the symbolic importance of water: its presence depicted in a framed television display, further enclosing and intensifying its meaning.

Figure 8: Collected wooden logs and river rocks used in the project.
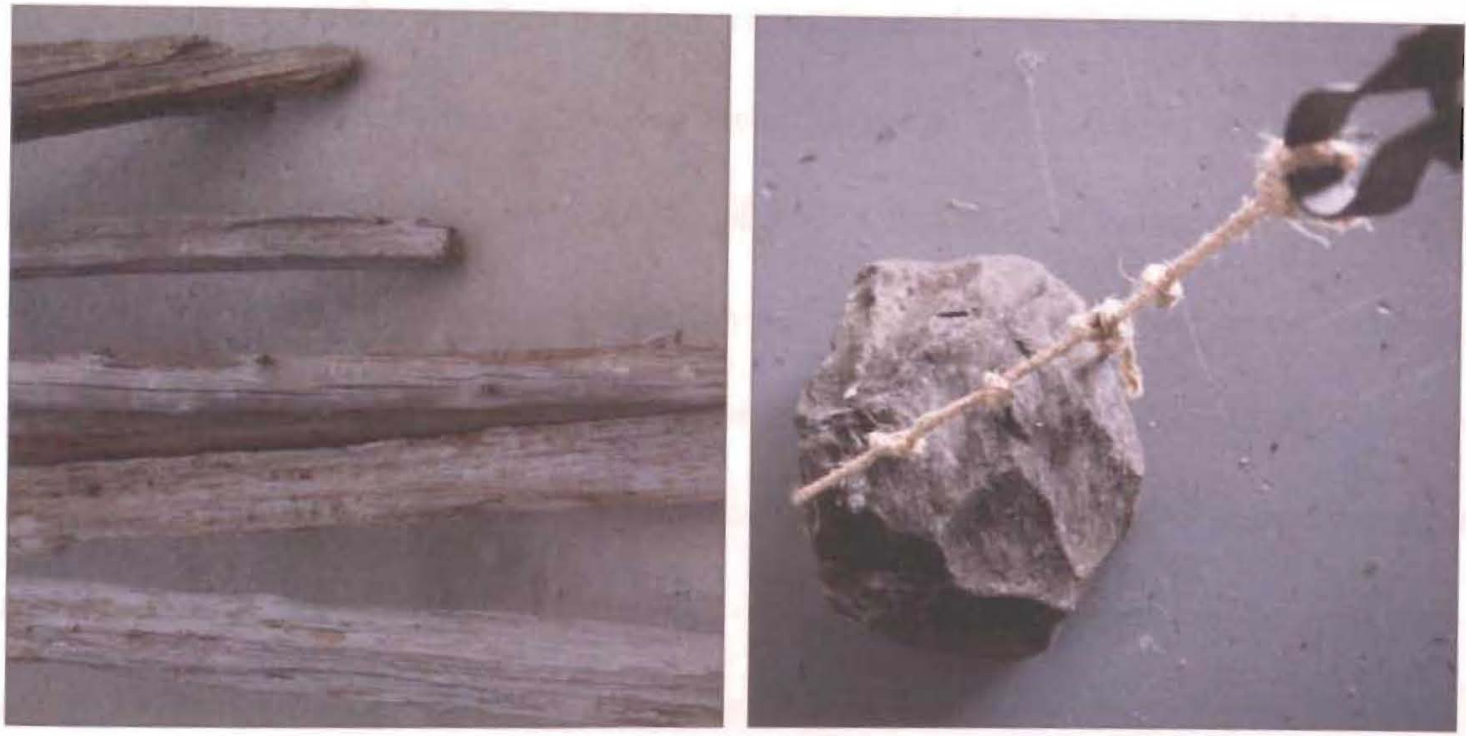

My persistence to use natural objects in this project took me on a trek to a nearby river, where I found two heavy rocks I selected to balance the wells' wooden arms. The arduous task of carrying the heavy rocks from the riverbed to my studio became an important part of the artistic process. This very act was something that could not have been preconceived in the planning stage of the project and thus became an unexpected visceral descriptor of the physicality permeating from the real wooden well structures that I had experienced in the past.

The audio component of this project comprises the crucial phenomenological element which aims to provide the participant with a reflexive environment in which sound 
is used as vehicle of detachment from the physical space, and acting as an attempted gesture of silent understanding. Each metal bucket in this art installation houses a built-in speaker which is connected to one of two audio channels, thus emanating distinct sounds and establishing a notion of a dialogue between each wooden well, where the disparate at time individual sounds eventually mesh into a cacophony of resonance. This attempts to provide the viewer of the installation with a setting focused on the intensity and the meditative power of the sound comprising the audio piece. This element of reverberation of space and time alludes to the hypnotic style of tintinnabulation, introduced by the Estonian composer Arvo Pärt, who poetically describes it as "a need to concentrate on each sound, so that every blade of grass would be as important as a flower" (Supin 00h12m39s). The immediate simplicity of Pärt's music stems from "an extreme reduction of sound materials and a limitation to the essential" ("Arvo Pärt - Biography"). This, I believe, presents the listener with a unique opportunity to confront the raw anatomy of the reality in which the artistic experience is being conveyed.

My work on the audio composition began by creating a richly textured reverberation based around single notes. Using a software synthesizer capable of subtractive synthesis and frequency modulation synthesis, the compositions acquired a sense of ordered randomness created in the gaps between each note (Figure 9). I first started composing the audio track in a recording studio, where I monitored the sound using headphones and high quality speakers. Although this was the preferred method of mixing sound, I soon realized a growing disconnect between the audio component and the raw materials of the yet to be built crane wells. This prompted me to move the audio station to my work studio, 
where I built a quick arrangement of a wooden log with the two metal buckets suspended from each end. It was then that I realized the clashing quality of the newly created audio track and the obvious imbalance it was introducing to the entire project. Further attempts to incorporate varying instruments, with the hopes of finding the "right sound," only

Figure 9: Selection from one of the first attempis in the audio composition.

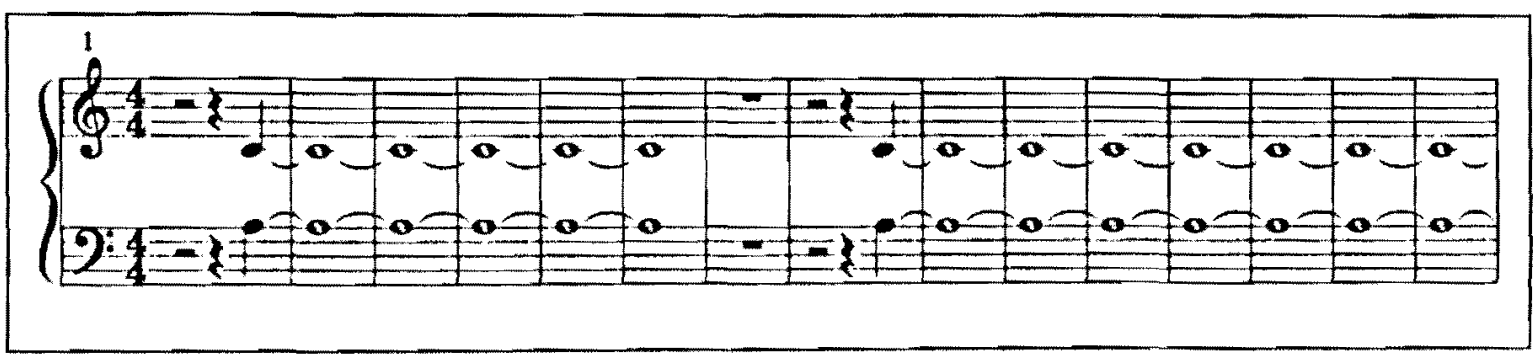

increased the disconnect between the materiality of the installation and the audio component it was to encompass. In the attempt to reconnect the two elements, I reinitiated my approach by omitting the use of instruments and synthesized sound, and shifted my attention to more elementary sounds. I started experimenting with various temple bells, each time focusing on the natural resonance generated between each strike. My conviction grew that this was the sound I wanted to incorporate, as the delicate reverberation seemed to capture the reflexive essence I was trying to evoke in this installation. Figure 10 illustrates a section of the finalized bell composition, where one note is played and then sustained for a number of bars. The single note phrasing extends the space of the composition, where the attack and the long sustain of the bell establishes an opportunity for an introspective reflection. 
Figure 10: Section of the final audio composition.

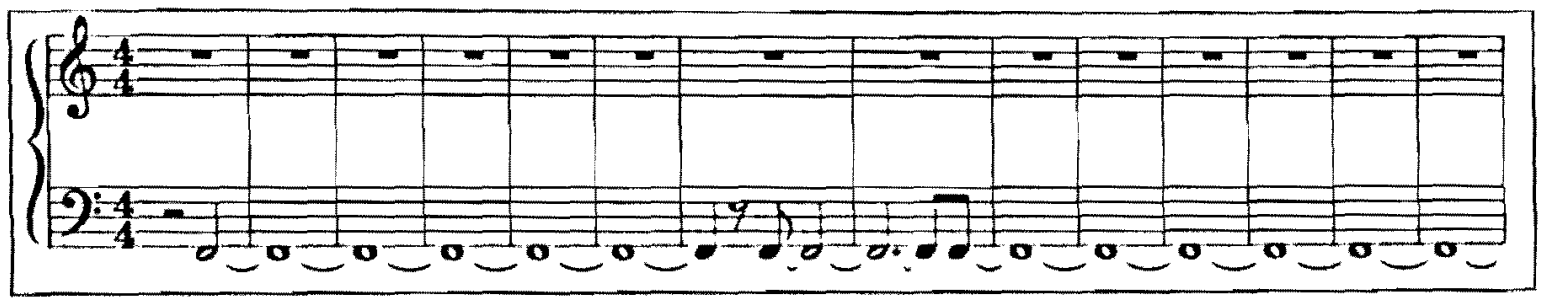

The resonating bell composition is interwoven with sounds of Polish harvest songs recorded around the 1940s, as discussed in the earlier part of this paper. The Institute of Art of the Polish Academy of Sciences in Warsaw has graciously granted me access to its immense collection of archival Polish folk music, and with the co-operation of the curator of the collection, Mr. Jacek Jackowski, has permitted the use of several chosen recordings for this project. The decision to use pre-recorded materials from the ISPAN collection lies in the indisputable essence of the historical energy captured in these recordings. Although I was initially inclined to incorporate my own audio content planned to be captured during a brief visit to Poland in early spring, I understood the significance of using pre-recorded material after a conversation with one of my thesis advisors. The use of these archival audio samples in my project was not only a way of making a small symbolic contribution in the effort to revive this rapidly fading part of cultural history, but also a way of reincarnating a certain portion of the spirit still resonating in these recordings. The current ongoing attempts to restore and digitally preserve these delicate sounds, originally recorded on very basic, almost archaic equipment, can certainly be seen as a way of emphasizing the faith in technological renewal. However, the very act of digitizing these sounds becomes a process of deconstruction, where the analog signals are remoulded into an array of complex and 
sterile digital impulses. As such, one notices how this almost ritualistic methodology concurrently introduces the danger of sanitizing the historic essence of these objects. In addition, with the imminent global conversion of all analog communication to digital format, I felt it was important to respond with a metaphoric act that could be seen as an attempt to retain the originality of the fragile fabric of these old recordings. This resulted in introducing an analog FM radio transmitter to the art installation, as well as an old portable transistor radio I found at a thrift store. The old radio is centrally positioned between the two crane well structures, and is used to emit the sounds of harvest songs broadcast via the hidden FM transmitter. I believe this introduces an interesting conceptual layer to this project, and channels an overlay of symbolism stemming from the cultural history embedded in the installation, while concurrently addressing the contemporary situation.

The process of building the two crane well structures proved to be a truly reflective experience; the act of working with the raw material heightened my sense of awareness about the essence of the project and its symbolism. Wells are endowed with an overlay of sacred significance and are perceived as channels of communication with the cosmic orders, thus thought of as providers of life and knowledge (Chevalier and Gheerbrant 1095). The well enables access to a clean water source, poetically denoted by Cirlot as "the universal congress of potentialities" (365). Clearly the primary source of life-sustaining water for village households, the act of drawing water from the well becomes a significant ritualistic act of receiving the gifts of the Earth, and in turn, "expresses a spiritual reality" (Campbell, "The Power of Myth" 92) so deeply interwoven in the sacral code (Sulima) of Polish peasant culture. Although I relied on historic documentation to reproduce the construction 
of the wells, I paid equal attention to my memories of watching family members working with similar materials in the past. This allowed me for the first time to really appreciate the act of repurposing weathered wood, while maintaining its tactile quality and a sense of history. As I worked alone, the act of joining various wooden parts of the well with straw rope (Figure 11) became an intensely intimate performance, where wrapping the rope Figure 11: The process of wrapping the straw rope and its finished form.
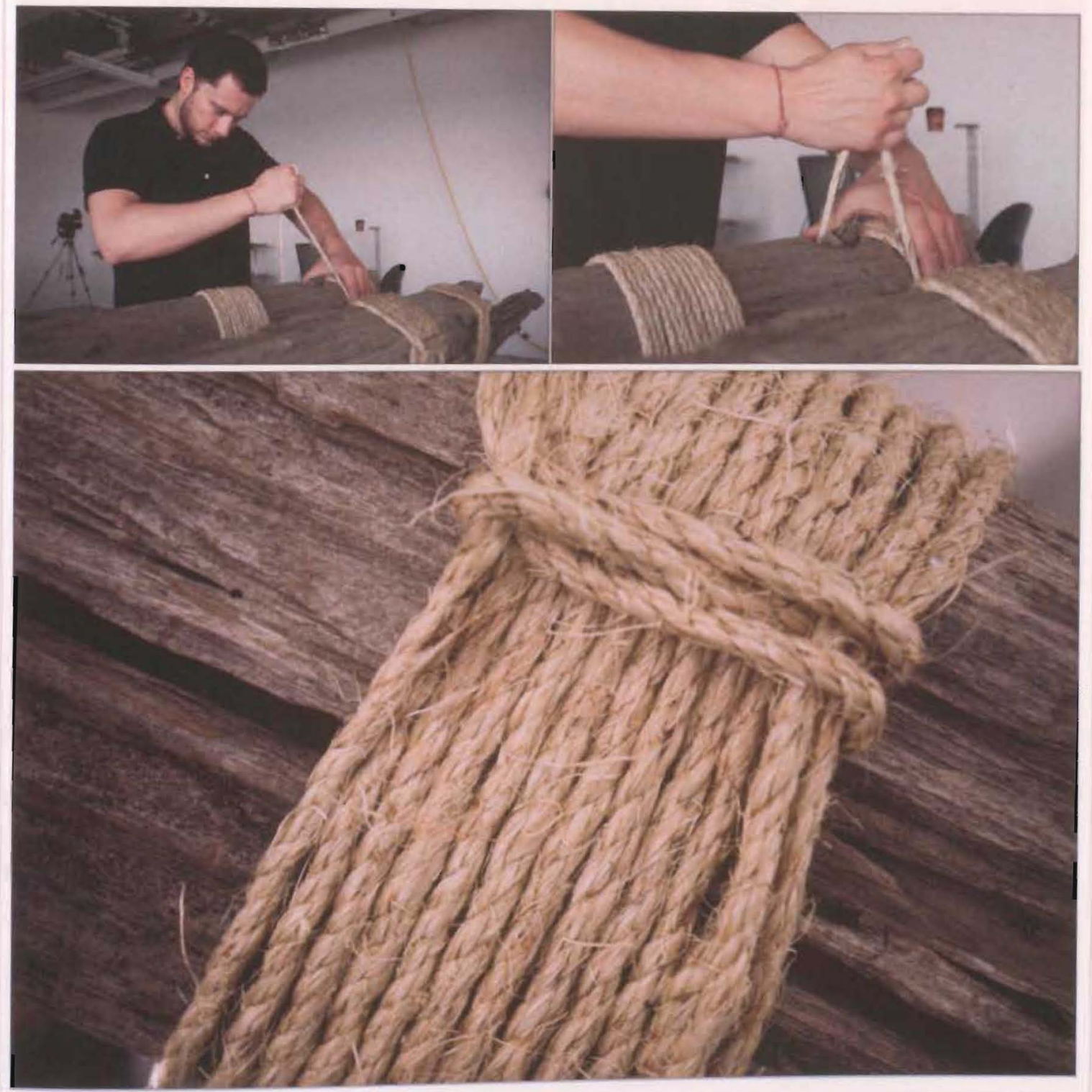
around the wooden logs required meticulous attention and often resulted in bleeding due to its rough texture. I humorously considered this to be a gesture of initiation: a way of reexperiencing my roots in a place where the clash of cultures often makes such articulation

Figure 12: Detail of the well's arm with the suspended water bucket.

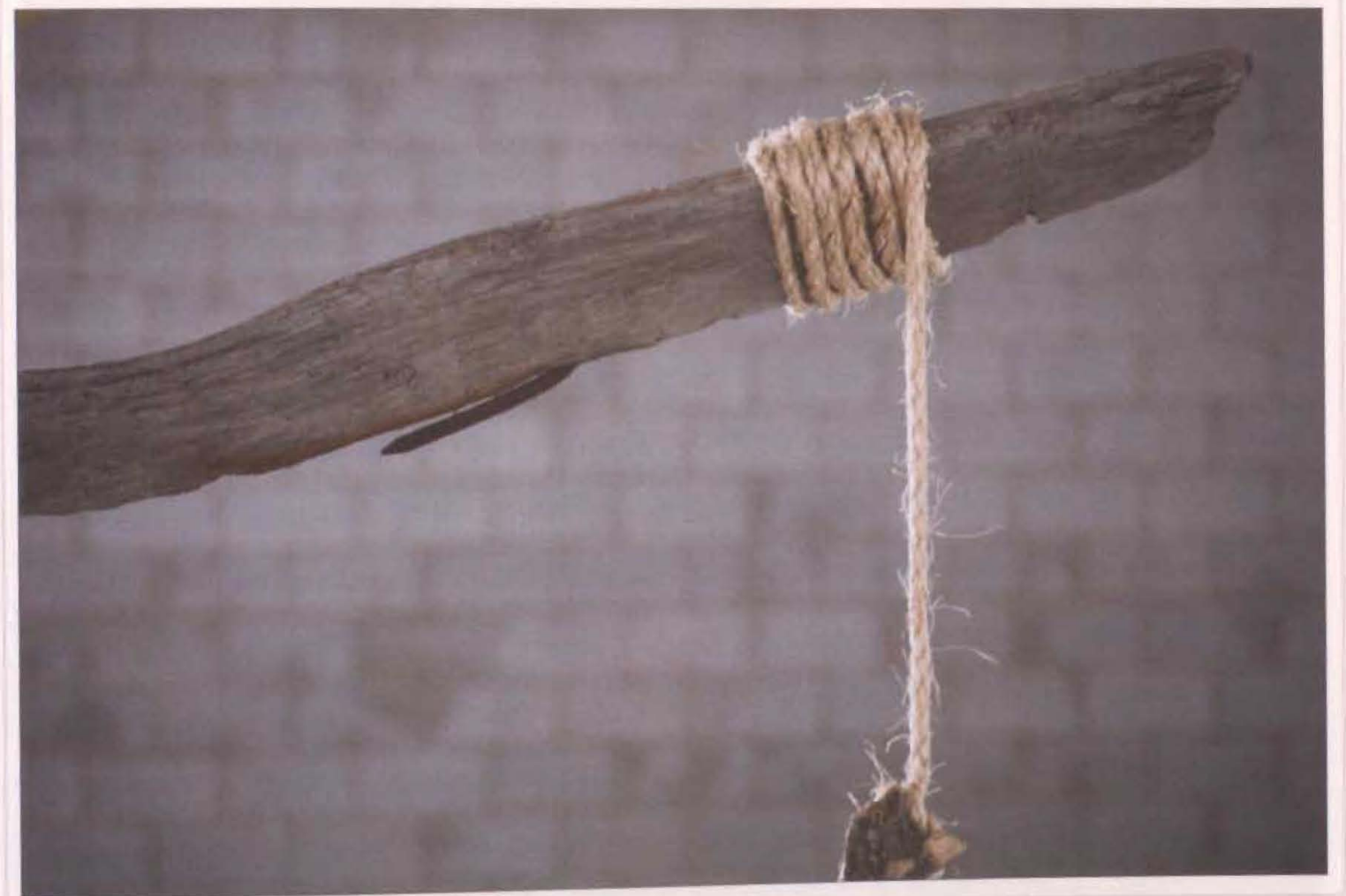

difficult. The final act of hanging the metal bucket on one end of the crane marked the symbolic finale and acquired a certain sacred significance. It was not feelings of nostalgia that preoccupied me at that moment, but rather, a sense of fully actualized connection with the previously inconspicuous forces constructing my identity. 
Figure 13: The completed art installation.
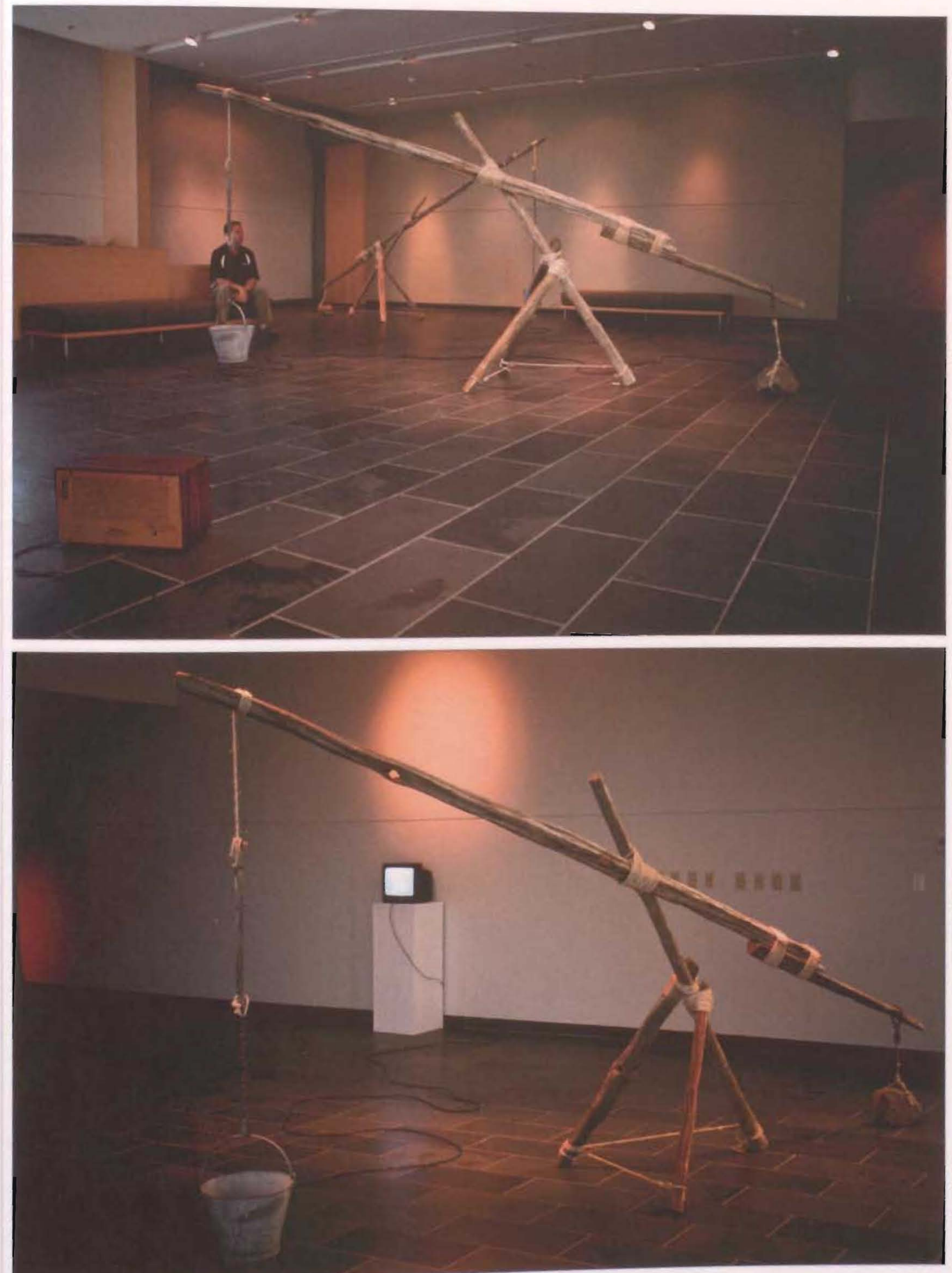
Figure 14: The completed art installation.
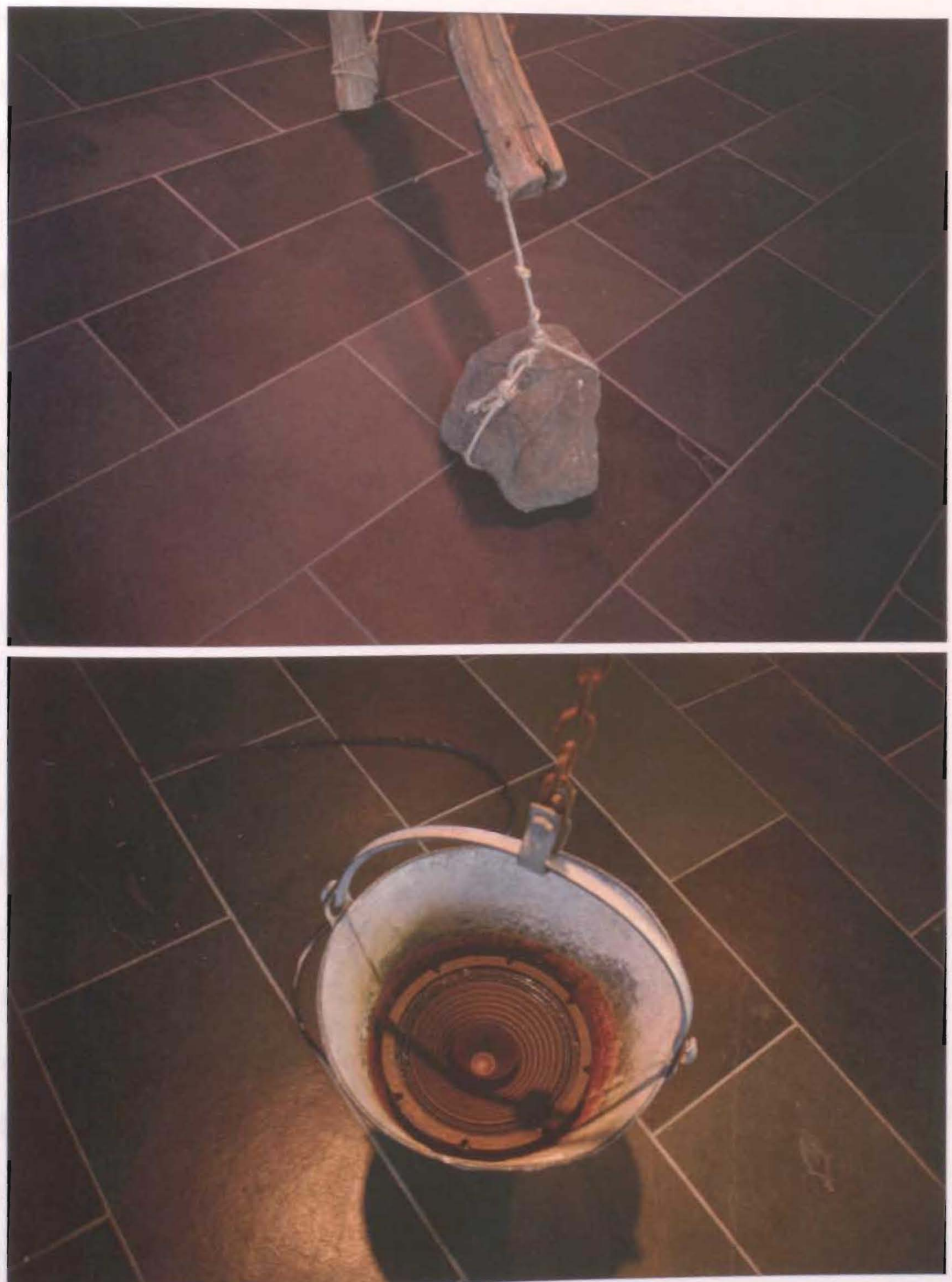
The dynamism of the artistic process undertaken to complete this installation resulted in a highly symbolic material manifestation, which attempts to regenerate the process' dynamics through stillness. The intended interpretation of the essence conveyed in the artwork, however, is recognized to be highly dependent upon a complex array of cultural, thus ideologically shaped assumptions. The final part of this paper takes a theoretical survey of the artistic process, where it examines the forces affecting the communicated message and the plasticity of its essence.

\section{Surveying the Artistic Process}

\section{Art as Communication}

The act of producing artistic works can be described as an orchestrated flow of communicative signals; a vehicle for assigning meaning to experiences (Foss and Littlejohn 39) encompassing the creator and viewer of the work. This movement is often argued to exist within the realm of a purely individual intent, acting as the conveyor of what is deemed thoroughly personal. The echoes of individuality in artistic expression dissipate, however, as one considers the view that meaning is something that is created rather than discovered (Smith 496). It is here that artistic expression acquires a new dimension in the context of interpretative processes, where the channels of discursive schema require new receptive meditation on the way imposed notions are embedded in personal expression. The plurality of the processes embedded in the act of artistic expression serves as the basis 
for questioning the purity of essence occupying personal forms of creative communication in the context of ideological formations. The communicative cycle of artistic creation and interpretation is argued here to depend on socially negotiated elements enveloped by ideological structures.

The inescapable multitude of narratives defining artistic expression creates a logical entry point for a discussion about some of the commitments bound to the definition of art. Such commitments stem from a juxtaposition of varied interpretations integrated in the discourses of phenomenology and structuralism, among others. The Hegelian rhetoric treats artistic expression as a significant movement to reveal the collective consciousness of humanity. Hegel asserts that art expresses the ethos of cultures and acts as "a necessity in the development of the Absolute Idea towards self-realisation" (Hatt and Klonk 24). This postulation can be further extended into the proposition that artistic process enables an expression of the human quintessence, and thus gives shape to more rational selfawareness, propelling one's striving for the Truth. In his account of the synthesis between the subjective and the objective, Hegel presents the notion of the Universal Spirit as the state of awareness on the highest level of human consciousness (Hegel, "Phenomenology of Spirit"). The Hegelian view of consciousness is one of the most fundamental existing phenomena in human beings; one that is further intensified through personal reflection. This notion is further extended by the proposition that each historic stage unveils a different representation of the Spirit, thus infusing the art's viewer with a new level of awareness. As one establishes the notion of art as being intimately embedded in the culture it serves through representation, the proposition of artistic expression as a source 
of knowledge arises. Art's ability to disclose certain elements of Truth makes it a vehicle of revelation, where the process of de-concealing and revealing further infuses knowledge. Although Hegel implicitly states that "[...] neither in content nor in form is art the highest and absolute mode of bringing to our minds the true interests of the spirit" (Aesthetics 9), one must realize that if art is a conveyor of certain truths, its messages cannot be blindly accepted. Seen as a cultural product, art has a submissive structure, fully malleable by its creator and fully susceptible to becoming a manipulative force. It is this force that allows artistic expression to project a certain level of authority upon the culture it resides in.

\section{Communicative Impulses}

Artistic expression is born out of the desire to express obscured facets of life, where the artistic process becomes a method of meditating on the ways to manifest otherwise indescribable observations about the reality surrounding the artist. The sensory involvement in the creative process initiates a heightened response to the act of articulation between the reality and the artist's inner experiences. This distinct method of communication is intrinsically embedded in every type of creative expression and becomes a way of assigning meaning to a particular set of experiences. It is a dynamic process that not only concerns a unidirectional flow of emotion, but rather presents itself as an ecosystem of self-discovery, where the act of creative communication redesigns the very building blocks of the artist's experiences, thus intensifying and possibly reshaping the scope of communicated ideas. This phenomenological approach becomes a method of 
ontology through the process of communication.

In support of the argument that " $[\ldots]$ the distinctive function of the artist is to express emotions; that if the artist does not express, his work is to that extent less entitled to be called art; and that all art must be expressive of something or other, so much so that a non-expressive work of art is a contradiction in terms" (Hospers 313), one must consider the influences propelling the process of expression. The seed of artistic creativity seems to originate from the depths of one's being. As the artist begins to articulate that which is to be externalized in the form of an artwork, an array of social constructs come into play. The propensity to elaborate on the transfiguring representation of personal reality seems to coexist in a strong bond with elaborate cultural elements that the artist happens to ingest. In this process, "[the] presentational reality is charged with elements of our common, shared reality, and yet it creates the clearly identifiable vision which characterizes the work of art" (Swanger 34). The extent to which such representation is shaped by outside discourses, coupled with their distinct descriptions of reality, is the core issue in the exploration of purity of artistic expression. The desire to express personal experience requires a vehicle of communication, which in itself is argued to be the process of assimilation of experiences (Collingwood 8). As the process of communication is grounded in various cultural conceptions, artistic expression must therefore also be ideational and ideological, behaviourally bound to numerous cognitive and symbolic elements. The fluidity of such elements creates the perception of order: "it is the interaction of external conditions and internal constructions that forms the basis for human creation, response, and apprehension" (Lankford 15). The perception of artistic 
expression as a form of communication, in its "struggle to learn and to

describe" (Williams, "Mass Communication" 45), can be extended here to the notion of creative communication as a deliberate and intentional activity (Harries xiii). It is the very notion of intentionality which suggests that artistic expression cannot simply exist as oneway communication, as one further observes that "communication is not only transmission; it is also reception and response" (Williams, "Culture and Society" 313).

\section{The Process of Interpretation}

The introduction of the viewer into the artistic discourse problematizes the notion of purity in artistic works. Meaning cannot be actualized by the artist alone, but it is rather evoked through the dialogue between the creator and the work's viewer and can be paralleled with Saussure's (246) speech circuit model of the process of communication. Artistic expression, therefore, must be understood as a mechanism actuated by its audience in the process of manifesting their elementary values. It is here that one notices the underlying frameworks governing art's creation and evaluation, and furthermore, the capacity of artistic expression to project a form of authority upon its audience. The inclusion of the viewer in the artistic dialogue is therefore of utmost importance in the process of crystallizing artistic discourses, and it is argued here that the process of interpretation of artist-instigated notions becomes further infused by ideological models.

This new dimension acknowledges the acts of creation and interpretation as being integral to aesthetic experience. Although the exploration of the complexities existing 
within the signifiers alluring the audience to participate in the artistic experience extends beyond the scope of this paper, it is crucial for the thesis to observe the resonant presence of artistic experience, along with the interpretative processes leading to further augmentation of the audience's emotional response to art. The fundamental modes of analytical interpretation of creative works seem to stem from the methodologies of form and content analysis. This approach consists of a synthesis of both form and content, evoking a critical look into factual and fictional constructs of the artwork (Chaplin and Walker 9). According to Panofsky, "in a work of art, 'form' cannot be divorced from 'content' [...which] must also be understood as carrying a more-than-visual meaning" (168). The process of interpretation is central to this idea, as it is tied to the notion of "interactive dimensions" (Kress and van Leeuwen 116) observed in the context of interactions between the producer and the viewer of images (114). Kress' and van Leeuwen's analytical rhetoric of the grammar of visual design easily translates into the interpretative methodologies of artistic works. The final reception of the work is dependent on a wide array of communicative elements employed by the artist. It is here, that "the articulation and understanding of social meanings in images derives from the visual articulation of social meanings in face-to-face interaction" (Ibid. 116), which ultimately underlines the notions of representation versus enactment. Kress and van Leeuwen further argue that social relations are not enacted, but rather, represented in the context of reception. The artistic lexicon enables representation through a system of signs, and just like language, it requires a "collection of necessary conventions that have been adapted by a social body to permit individuals to exercise [the faculty of 
speech]" (Saussure 245). The high complexity of artistic vocabulary employed by the artist can therefore impede the interpretation of the work, resulting in utilization of mixed conventions of collective behaviour (Saussure 252) to interpret the true meaning of the artwork. The multivalence of symbolic communication requires multiple methodological approaches, further limited with the proposition that works of art are not restricted to symbolic representations: "a feeling generated through an encounter with a work of art also constitutes part of the total significance of that work" (Lankford 153). Here, the interpretative process no longer relies on the presence (or absence) of the linguistic message. Instead, it puts "our experiences with the physical world [to] serve as a natural and logical foundation for the comprehension of more abstract domains" (Kövecses 6). But even the essence of experiences with the physical world can be speculated to stem from the acceptance of interrelated views believed to represent the Truth. Perlmutter and Koppman (89) argue that "every viewing of art simultaneously involves an act of interpretation, conditioned by the viewer's culture, biases, and experiences," which indicates that one must consider the continuously evolving culture structures and their prevailing attitudes in the complex matrix of varying receptions and interpretations.

Barthes (146) posits that the proper reading of text requires deliberate separation from the author's various social, religious and political attributes. He writes: "we know now that a text is not a line of words releasing a single 'theological' meaning $[\ldots]$ but a multi-dimensional space in which a variety of writings, none of them original, blend and clash. The text is a tissue of quotations drawn from the innumerable centres of culture" (146). As suggested here, the invocation of knowledge through art has a 
multidimensional aspect, one that requires a thorough interpolation of "influences, symbolism, iconography, and cultural history" (Koppman 91). Is it possible, however, to consciously separate oneself from ideological undercurrents penetrating artistic expression and thus achieve a more objective interpretation? The process of seeking meaning seems to be elicited through the mechanism of interrelatedness, as meaning is posited to always exist in the act of referring to something other (Merrell 4). The act of referral to representational units of knowledge can be argued to be a negotiation between reality and perception, unveiling here the intertwined fluidity of this process. "A representation [...] is always of and to and for" writes Heath (91), positing that representation is an act of production of imagined depictions and substitutions. As such, the validity of Truth in the process of interpretation seems to fail in its depiction of authentic reality. If representation is indeed linked with identification as Heath (97) seems to suggest, one could conclude that the main determinant of the degree of objectivity in artistic interpretation stems from the fluctuating structures propelling the process of identification.

The dominant, negotiated, and oppositional readings of codes identify the various modes of naturalizing perception (Hall 56), further extended through the levels of connotation and denotation. Although not universally deterministic, Hall's rhetoric of the process of encoding and decoding further bolsters the aspect of social conditioning as the key element in the articulation of artistic experience through interpretation. The general attitude of the Saussurean tradition suggests that culture is the main constituting element of the human experience (Hatt and Klonk 205). As such, the reception of coded meaning relies on the complexity of social factors and their capacity to convey preferred modes of 
interpretation. This, in turn, generates methods of normalization and naturalization of ideological structures of knowledge. Such processes are not only employed on a personal level, expressing the preferred attitudes of specific social environments, but are also propagated by institutional spheres. The domain of art criticism steers the viewers into formally established "proper" identifications of artistic meaning. Its evident position as a state ideological apparatus (Althusser), is very much intertwined in the complex social grid, thus creating an atmosphere of approved Truth which further "elevates whatever the artworld does, as a matter of 'descriptive' fact, into the going norm, by virtue of the fact that this is the going norm" (Wartofsky 241). It is important to notice, however, that the ideological formations evident in the institutional theories of art stem from a much wider range of socio-political viewpoints, each committed to a set of individual attitudes. As such, the constraining characteristic of singular commitments to art interpretation also has a positive outcome: it allows the sampling of a variety of inquiries about the work's representation of reality. This leads to the possibility of meeting the deficiencies of singleminded notions, thus expanding one's capacity for a fuller experience of art. Power relations are evident in the way ideological notions shape one's capacity to experience the reality conveyed in works of art. One of the critical components of power, argues Foucault (1995), is the ability of the oppressed to resist the discourses of the dominating structures. As such, the pervading nature of power is not purely oppressive in nature, but also exhibits an element of positive productivity, "[...] giving rise to new forms of behaviour rather than simply closing down or censoring certain forms of behaviour" (Mills 33). This act actualizes the freedom of interpretation, where the previously established notions of the 
Truth are no longer constrained by their founding ideologies, but rather provide an opportunity for reflection and potentially deeper, personal experience of a work of art.

\section{Conclusions}

The artistic process cannot be compacted into a series of procedural phases, actuated by the desire to express the many intricacies of life. The process of creation often lies in one's inability to face the emotional echoes of the permeating reality, striving to externalize that which is often deemed indescribable. Initially stemming from a highly individualistic endeavour, the artist attempts to engage the audience to participate in his or her experience: the process through which a culmination of emotions is attained by coded signs, where "[...] the feelings [the artist] has experienced, and in others being infected by those feelings and also experiencing them." (Tolstoy 40). The mental representations of the artist are therefore further externalized by the involvement of the audience, who, by the initial communicative processes instigated by the artist, can be compelled to encounter a similar emotional response to the work. The completion of this process relies on the audience's initial attraction to the work of art and its embedded meaning. Such attraction can derive from personal interest in the essential theme explored in the artistic work, or simply a curious attempt to expand one's knowledge from art's stream of truths. On a more visceral level, the attraction could stem from a sense of awe in the presence of highly expressionistic artistic expressions, thus further sustained by the stylistic integrity of the work and its inherent ability to offer sensory satisfaction. The inherent complexity of the 
artistic process (Figure 15) introduces several entry points at which the essence of the artistic expression becomes skewed. The multitude of cultural conceptions enveloping the individuality of the artist inarguably decentralizes the striving for objective representations.

Figure 15: Notion of purity of essence in the process of artistic expression

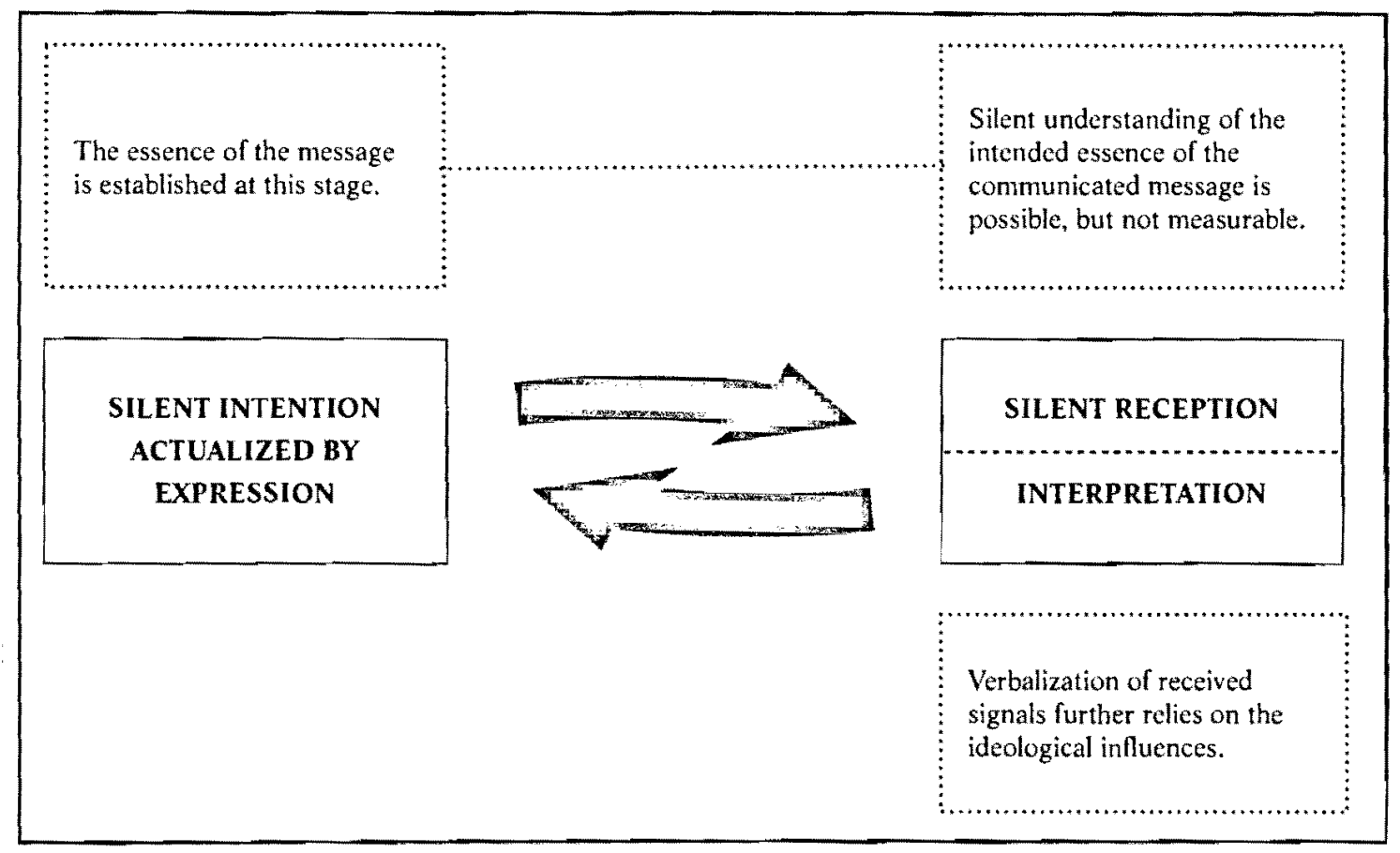

The attainment of empirical expression in art seems impossible as the descriptions of reality are always relational, and furthermore, the act of interpretation further relies on the rich array of cognitive mechanisms influenced by ideologically grounded structures.

It is this thesis' careful conclusion, that the absence of sustained purity in artistic expression should not be considered as entirely unfavourable to the whole of creative expression. Lankford (157) suggests that the multitude of experiences surrounding the viewer of art allows for a potential synthesis of experiences culminating in a heightened, perhaps clarified response to the work. "Reflections upon the meaning of a work of art, 
continuously verified and enriched by immediate perceptions, may extend a viewer's experience of that work beyond what is visibly given or even beyond particular symbolic meanings, but still within a context of relevance" (Ibid. 157). The admission of the dominance of multiple ideological stances is also present in the rhetoric of W. J. T. Mitchell ("Showing Seeing" 87), who posits that vision is a highly cultural construction thereby making images entirely saturated with language. As such, visual images should no longer be regarded as single-dimensional representations, but rather, analytical approaches should be formulated in multiple contexts of representations (Mitchell, "What Do Pictures Want?" 33). The attempt to avoid ideological influences in the process of artistic expression would require a response to the very principle of personal experience. As meaning is undeniably produced in social contexts, the ideal act of interpretation must be performed with the full awareness of the often subtle variances in socio-political perspectives. The resulting multiplicity of interpretative propositions would then offer the potential of uncovering the determining modifiers used in the conditioning of socially based facets of interpretation.

I write these concluding remarks with a much stronger sense of inner understanding, which has been built upon the synthesis of intellectual and practical approaches this thesis allowed me to undertake. The creative process undertaken in this project has registered an immense value in the realization of my cultural identity and its position within the larger cultural landscape. My commitment to praxis has undeniably provided clues of sacrum's interwoven existence based on personal experience as the 
source for shaping the measurable reality and thus arriving at Truth. It was of utmost importance to me, however, that my artistic process was not merely regarded as autobiographical in nature, but instead aspired to evoke an understanding of the nucleus in the message I was trying to communicate. Throughout this process, I had informally asked random visitors to comment on their interpretation of the progressing installation. Interestingly, although most respondents were not familiar with the purpose of the structures, as wooden crane wells are foreign to North America, a vast majority expressed a strong sense of underlying symbolic influences stemming from a rich array of cultural history. The sacredness of the installation was argued to exist in the stillness of the wooden structures and the richness of the audio portion, which provided a reflexive environment for the participants. Although I did not see the extraction of the viewer from the artistic process as detrimental to the experience of the final work, I attempted to perform a critical enquiry about the process of interpretation and deduce how the highly symbolic notion of sacrum was being conveyed. As shown, I have put strong emphasis on the holistic epistemology, which I believe is crucial in the attempt to detect and understand the essence of such experiential notions as that of sacrum. I recognize that sacrum's resonant positioning requires bold transgressions of the established modes of knowledge, transcending the tensions between the varying representations of reality. The holism of interpretative approaches lies in the need to attain a fuller awareness of varying cultural perspectives and their governing rules of perception. This, I believe, is needed to avoid the dissemination of absolute truths concerned with protecting us from the supposed chaos of our reality. Such movements often only demarcate us from discovering the deeper meaning of our interiority. The implications of the diversity of results stemming from 
varying analytical practices are an unavoidable but rather welcomed consideration, due to their unmistakable potential for providing theoretical refinement of the multiplicity of notions. I feel that the expansion of the existing discursive systems can thus enable a better reflection of the complex continuum of cultural representations and provide a multidimensional approach to enable a deeper exploration of the essence of transcendental notions.

The actualization of my newly acquired understanding was heavily dependent on the analysis of resulting interpretations belonging to the viewers of this art installation. I saw this as being crucial to the formulation of this project's ultimate effectiveness, as I am again reminded about the reciprocity of the communicative cycle, where meaning is realized through articulate expression (Williams). Central to this analysis is the consideration that multiple interpretations of highly metaphorical elements implicate their validity as quantifiable data. After all, art products carry an immense possibility of conveying a specific emotion on multiple levels, therefore generating a barrage of possible interpretations. Furthermore, Mircea Eliade posits that symbolic communication is capable of expressing potentially inexpressible notions, as they "[...] reveal a modality of the real or a deep structure of the World, and in the spiritual horizon of primitive man, the real mingles with the Sacred" ("Symbolism, the Sacred, and the Arts" 3). Grounded in the experiences of life, such expressions are binary in their purpose as they convey transcendental notions in the context of human experience: "symbols not only disclose a structure of the real or even a dimension of existence, at the same time they carry a significance for human existence" (Ibid. 5). One has to be careful when dictating how an expression of creativity is to be interpreted and must not insist on its "proper" reading. 
Given this subjectivity, how can one quantitatively measure the effectiveness of an artwork and furthermore, determine its legitimacy as a social document? With a limited set of accepted unorthodox research methodologies, it is difficult to rely on alternative research mechanisms while maintaining their validity as data. I argue that measuring highly experiential events is doomed to become a fruitless endeavour, as it relies on the ability of the researcher and subject to use verbal descriptors to convey non-sensual content. As described in the earlier part of this paper, the most viable approach to studying such experiential notions - as that of sacrum, for example - requires the avoidance of thinking in terms of absolutes. The approaches employed by the doctrines of history or aesthetics, for example, should not be regarded as an exhaustive means of deliberating the truth, but rather, as introductory tools of expanding the boundaries of knowledge. It is evident that the detection of sacrum's subtle elements requires the illumination of a multitude of disciplinary approaches, which - from a holistic point of view - will provide us with a means of attaining understanding through recognition. Such recognition is the constituting element of this project's practical outcome. The applied aspect of praxis presented in this proposal propagates the notion of "seeing knowledge at work" (Bronner, "Art, Performance, and Praxis" 91) by means of personal reflection, analysis and reinterpretation in the attempt to provoke the manifestation of human instinct for transcendence (Eliade, "The Sacred and the Profane" 27). I have attained this state of personal recognition through the methodology of praxis, and it is my sincere hope that the resulting work will evoke similar realization in its audience. I hope that the methods described in this paper will provide such insights, and further elicit the effectiveness of artistic practice in the exploration of the vast landscape of human essence. 


\section{Bibliography}

Althusser, Louis. Ideology and Ideological State Apparatuses. In "Media and Cultural Studies: Keyworks." Eds. Durham, Meenakshi Gigi, and Douglas Kellner. New York, NY: Wiley, 2005.

In this influential essay, summarized are the core theories pertaining to ideological methodologies propagated by organizational structures. The main focus is on Ideological State Apparatuses such as educational and religious systems.

Apostolos-Cappadona, Diane. Introduction. Symbolism, the Sacred, and the Arts. By Mircea Eliade. New York: Continuum International Publishing Group, 1992. ix-xxi.

Arvo Pärt: 24 Preludes for a Fugue. Dir. Dorian Supin. DVD. Juxtapositions, 2005. Shot over a five-year period, the documentary is a collage of vignettes depicting Pärt's artistic process. Although edited in a somenthat an'kward fashion, the film paints a fascinating picture of this composer's musical genius.

"Arvo Pärt - Biography." Universal Edition- Internationaler Musik- und Bühnenverlag. 10 June 2009 <http://www.universaledition.com/truman/en_templates/ view.php3?f_id $=146 \&$ komp_uid $=534 \&$ spr $=$ en $>$.

Barber, Renate C. "Sacred and Profane: Some Thoughts on the Folk-Urban Continuum of This Dichotomy." Man 65 (1965): 45-46.

Rooted in Durkheim's dichotomy between the sacred and the profane, Barber elaborates on the 'fuzziness' of the borders between the sacred and profane based on one's level of involvement in the society's religious life.

Barthes, Roland. Image-Music-Text. Redlands: Fontana Press, 1993.

This classic text is comprised of essays surveying the codification of visual, audible and textual content. These seminal essay's introduce Barthes' key semiological terminology.

Baumann, Richard. "Verbal Art as Performance.” American Anthropologist 77.2 (1975): $290-311$.

In this study, verbal art is presented as a performance-centred conception. Depicted are various theoretical approaches to artistic actions and events and how they are actualized by performance. 
Becker, Judith. "Music and Trance." Leonardo Music Journal 4 (1994): 41-51.

This is a fascinating study of the relationship between the state of trance and music. As an authority on the music of Southeast Asia, Becker presents her research in brain topography and applies it to the noetic quality of music-induced trance.

Benjamin, Andrew. Walter Benjamin and Art. New York: Continuum International Publishing Group, 2005.

A thorough analysis expanding Walter Benjamin's "The Work of Art in the Age of Mechanical Reproduction."

Benjamin, Walter. "The Work of Art in the Age of Mechanical Reproduction." Media and Cultural Studies: Keyworks. Ed. Meenakshi Gigi Durham. Douglas M. Kellner. Malden, MA: Blackwell Publishers, 2006. 18-40.

Benet, Sula. Song, Dance, and Customs of Peasant Poland. New York: Hippocrene Books, 1996.

A thorough anthropological study of the Polish peasant culture. Detailed descriptions aimed at depicting the characteristics of Polish peasantry in the first half of the XX century. Also recommended is the book by Sophie Hodorowicz Knab: "Polish Customs, Traditions and Folklore."

Bronner, Simon J. "Art, Performance, and Praxis: The Rhetoric of Contemporary Folklore Studies." Western Folklore 47.2 (1988): 75-101.

A critical essay examining various approaches to the study of culture and society. By focusing on the scholarly use of art, performance and praxis, Bronner illustrates the reciprocal outcomes of interpretation of tradition through the eyes of modern experience.

Bronner, Simon J. "Investigating Identity and Expression in Folk Art." Winterthur Portfolio 16.1 (1981): $65-83$.

Bronner discusses a behavioristic approach to the study of folklore. Illustrated are potential contributions of this methodology based on the exploration of human behaviour and thought in a community setting. Bronner uses examples from his own field research and references Michael Owen lones' work.

Campbell, Joseph, and Bill Moyers. The Power of Myth. New York: Anchor, 1991. Published as a companion to the 1988 PBS documentary under the same title, the book documents the dialogue between Campbell and Moyers. A beautiful encapsulation of Campbell's enlightening view of the mythic world. 
Campbell, Joseph. Myths to Live By. Boston: Penguin, 1993.

One of many of Campbell's must-read books. This text explores the application of universal myths in the life of the contemporary man. Also suggested are "Hero with a Thousand Faces" and the series: "Masks of God."

Chandler, Daniel. Semiotics: The Basics. New York: Routledge, 2007.

The definite guide to the field of semiotics. The first edition is freely available in digital format on Chandler's website: http://www aber.ac.uk/media/Documents/S4B/ index.html

Chaplin, Sarah, and John A. Walker. Visual Culture: An Introduction. Manchester and New York: Manchester University Press, 1997.

An overview of the subject of Visual Culture Studies and its interdisciplinary approach. The book discusses the notion of "culture" and "visual" by situating these terms in existing body of research and by providing new theoretical approaches.

Chevalier, Jean, and Alain Gheerbrant. The Penguin Dictionary of Symbols. Boston: Penguin (Non-Classics), 1997.

Cirlot, J. C. Dictionary of Symbols. New York: Routledge, 1990.

This text is highly recommended as a companion to "The Penguin Dictionary of Symbols" as it provides expanded definitions of the discussed symbols.

Collingwood, Robin George. The Principles of Art. New York: Oxford University Press, USA, 1958.

In this important critical inquiry into various definitions of art, Collingwood presents his own notions of art as a process of imaginative discovery positioned in a dialogue between the creator and the viewer. Along with Tolstoy's "What is Art?," it provides yet another insight into the meaning and purpose of artistic expression.

Czekanowska, Anna. Polish Folk Music: Slavonic Heritage - Polish Tradition -

Contemporary Trends (Cambridge Studies in Ethnomusicology). New York: Cambridge University Press, 1991.

An impressive study of the richness of musical traditions of Polish folk music with detailed exploration of the influences stemming from geographical, historical and political forces. 
Dikovitskaya, Margaret. Visual Culture: The Study of the Visual after the Cultural Turn. London: The Mit Press, 2006.

An analysis of the various theoretical approaches defining the interdiscipline of visual studies. Among the detailed overview of the field, provided are interviews with numerous visual studies scholars, further enlightening the reader with the multidimensional grasp of this interdiscipline.

Eco, Umberto. A Theory of Semiotics. Bloomington: Indiana University Press, 1976. This book expands the structuralist methodologies of communication by studying the dynamics of reciprocal construction of meaning between the producer and interpreter.

Eliade, Mircea. Images and Symbols. Princeton: Princeton University Press, 1991. Impossible to summarize, Eliade's writings are essential to a better understanding of the many sacred manifestations defining human existence.

- The Sacred and The Profane: The Nature of Religion. New York: Harcourt Inc., 1987.

- Symbolism, the Sacred, and the Arts. New York: Continuum International Publishing Group, 1992.

Feinstein, Hermine. "Meaning and Visual Metaphor." Studies in Art Education 23.2 (1982): 45-55.

Based on the premise that metaphor expands our understanding of the human experience, Feinstein discusses the importance of metaphor in the construction of meaning in visual and linguistic contexts. This paper makes a great companion to Eliade's and Kövecses's work.

Foss, Karen A., and Stephen W. Littlejohn. Theories of Human Communication. Belmont, CA: Wadsworth Publishing, 2007.

This seminal text gives an extensive yet very accessible introduction to the numerous communication theories. Discussed are the various applications of the studied traditions and their relationships with other theoretical methodologies.

Foucault, Michel. Discipline \& Punish: The Birth of the Prison. New York: Vintage, 1995. The Foucauldian rhetoric on power provides an interesting view of the techniques of power in relation to bodies of knowledge and their discursive formations. 
Gablik, Suzi. Has Modernism Failed?. New York: Thames \& Hudson, 2004.

An interesting, but rather gloomy view of the post-modern art scene, depicting the loss of direction in artistic practice. Gablik's notion of artist as a shaman is a cry for spiritual renewal in artistic expression. The text raises very interesting points, but should be read with an open mind due to its often criticized subjectivity.

Gralinska-Toborek, Agnieszka. "The Idea of Sacrum in Polish Art of the 1980s." Inferno VII (2003): 1-7.

An illuminating examination of the term sacrum during the transition of Polish art from modernism to post-modernism. The author discusses the emergence of nev interest in spiritual themes in artistic expression of the 1980s and provides several examples of artists working with the notion of sacrum in their practice.

Hall, Stuart. "Encoding/Decoding." Media Studies: A Reader - 2nd Edition. Eds. Marris, Paul, and Sue Thornham. London: NYU Press, 2000.

Classic study of the creation of meaning of text in the relation to its producer and consumer. Hall's theoretical framework is also discussed by Chandler in "Semiotics: The Basics."

Harries, Karsten. The Meaning of Modern Art: A Philosophical Interpretation. Evanston: Northwestern University Press, 1968.

Difficult to summarize due to its richness, this book presents a philosophical view of modern art and is a great companion to other texts probing the meaning of artistic expression,

Harris, Marvin. Theories of Culture in Postmodern Times. Walnut Creek, CA: AltaMira Press, 1998.

Written in the holistic spirit of an anthropological examination, this books examines culture and its constituting elements of ideas and behaviour. Enlightening and controversial, this is a fantastic supplementary text in the area of cultural studies.

Hatt, Michael, and Charlotte Klonk. Art History: A Critical Introduction to Its Methods. Manchester and New York: Manchester University Press, 2006.

$A$ very accessible analysis of the multitude of debates comprising the history of art. Offers a chance to reflect on the variety of binding methodologies and their ideological commitments. Also offers a concise overview of Hegel's philosophical premises. 
Hayward, Susan. Key Concepts in Cinema Studies. London: Routledge, 1996. An extensive companion to cinema studies with extensive discussion of varying theoretical approaches.

Heath, Stephen. "Keywords: Representation." Critical Quarterly 50.1 (2008): 87-99. $<$ http://www3.interscience.wiley.com/journal/119389277/issue>. A discussion of the notion of representation in the context authentic knowledge. An intriguing discourse, although somewhat complex and at times frustrating to read.

Hegel, G. W. F.. Aesthetics: Lectures on Fine Art Volume I (Aesthetics). New York: Oxford University Press, USA, 1998.

Hegel's philosophy is extremely complex, but highly fascinating. Most important application of this work to my thesis, is Hegel's view of art as a the means rediscovering oneself and attaining spiritual freedom.

- Phenomenology of Spirit. New York: Oxford University Press, USA, 1979. Most interesting I found Hegel's argumentation that human beings do not perceive the real world, but rather exist in a virtual reality based on ideas and perceptions. The evolution of the Spirit (the collective consciousness of the society), is achieved through reflection where it becomes "infused." An interesting connection to artistic expression as the enabler of such "infusion" arises here.

Hernandez-Albujar, Yolanda. "The Symbolism of Video: Exploring Migrant Mothers' Experiences." Visual Research Methods Image, Society, and Representation. Ed. Gregory C. Stanczak London: Sage Publications, Inc, 2007. 281 1-306. A case study of Hernandez-Albujar's qualitative project on migrant mothers in Italy, in which she incorporates a highly experimental, expressionistic video component as an integrative part of the project's ethnographic research.

Hospers, John. "Artistic Creativity," The lournal of Aesthetics and Art Criticism. 43.3 (1985): 243-255.

In this critical analysis of the creative process, explored are various approaches bound to the notion of creativity.

Izgnanie (The Banishment). Dir. Andrei Zvyagintsev. Perf. Konstantin Lavronenko, Aleksandr Baluyev, Maksim Shibayev. 2008. DVD. Soyuz Video, 2007. 
Jakitowicz Maria, Wróblewska Violetta. Podanie Legenda w Tradycji Ludowej i Literackiej.

Toruń: Wydawnictwo Naukowe Uniwersytetu Mikołaja Kopernika, 2007.

This collection of essays, originating from various Polish academic institutions, explores the vastness of Poland's verbal culture. Surveying a number of literary traditions, the book illustrates the fascinating history of Polish oral tradition and its amalgamation by the mass media. Of special interest to me, were numerous descriptions of sacred symbolism prevalent in Polish culture.

Jones, Michael Owen. "'Tradition' in Identity Discourses and an Individual's Symbolic Construction of Self." Western Folklore 59.2 (2000): 115-141.

Joselit, David. "The Video Public Sphere." The Visual Culture Reader. Ed. Nicholas Mirzoeff. New York: Routledge, 2002. 451-457.

A critical analysis proposing the use of experimental artworks to defy the constructs of commercial television by means of personal reflection, analysis and re-interpretation of the value systems.

Jung, Carl Gustav. Man and His Symbols. New York: Dell, 1968.

Although written for readers not well versed in psychology, this book captivates with the immense richness of Jungian theories. Built on the premise that symbols reflect man's silent unconscious, the book surveys the themes of dream psychology, art and mythic symbolism to define the significance of symbols in the detection of one's interiority.

Kandinsky, Wassily. Concerning the Spiritual in Art. New York: Dover Publications, 1977. This text is Kandinsky's elaboration on the purpose of modern art, and the need to transcend the materialistic engagement of art in order to awaken the audience's spirituality. A great complimentary read to the writings of Kubler, Hegel and Panofsky, among others.

Kövecses, Zoltán. Metaphor: A Practical Introduction. New York: Oxford University Press, USA, 2001.

An thorough discussion of the significance of metaphoric constructs from a linguistic perspective.

Kress, Gunther, and Theo van Leeuwen. Reading Images: The Grammar of Visual Design. New York: Routledge, 2006.

A comprehensive examination of visual literacy and its constructs used to convey meaning. 
Kubler, George. The Shape of Time: Remarks on the History of Things. New Haven: Yale University Press, 2008.

It is impossible to summarize the richness of this book in a few sentences. The essential discussion in this book is based around the historical significance of objects: the relatedness of time, history and creativity and offers an introspective survey of the dynamics of artistic expression. I found reading random passages of this book immensely helpful in developing the philosophical angle for my thesis.

Lankford, Louis E. "A Phenomenological Methodology for Art Criticism." Studies in Art Education. 25.3 (1984): 151-158.

An engaging discussion of new methodology for art criticism from an educative perspective. Discussed are the components of the proposed method, namely receptiveness, orienting, bracketing, interpretative analysis and synthesis.

Ling, Jan. A History of European Folk Music. Rochester: University of Rochester Press, 1998.

Surveys the evolution of immense number of folk music styles in Europe and discusses the relationships between their varying styles.

Merrell, Floyd. Peirce, Signs, and Meaning. Toronto: University of Toronto Press, 1997.

Mills, Sara. Michel Foucault (Routledge Critical Thinkers). New York: Routledge, 2003. A comprehensive but very readable examination of Foucault's key theories. This is a great introductory text to some of Foucault's more complex ideas.

Mirzoeff, Nichol. Introduction to Visual Culture. New York: Routledge, 1999.

Mitchell, W.J.T. "Showing Seeing: A Critique of Visual Culture." The Visual Culture Reader. Ed. Nicholas Mirzoeff. New York: Routledge, 2002. 86-101. An essay attempting to position the interdiscipline of visual studies in the academic field dominated by art history, aesthetics and media studies. Mitchell argues that we cannot separate images from other senses, such hearing and touch, and instead we are always dealing with mixed media representations.

- What Do Pictures Want?: The Lives and Loves of Images. Chicago: University of Chicago Press, 2005. 
Panofsky, Erwin. Meaning in the Visual Arts. Chicago: University Of Chicago Press, 1983. An anthology of works exploring the symbolism embedded in artistic representations. Very interesting is Panofsky's study of the intrinsic meaning of symbols as they reveal the general attitudes of the times.

Perlmutter, Dawn, Koppman, Debra. Reclaiming the Spiritual in Art: Contemporary Cross-Cultural Perspectives. Albany, New York: State University Of New York Press, 1999.

This is a strongly recommended compilation of essays discussing the various manifestations of spirituality in contemporary art forms. It offers a wealth of perspectives stemming from various theoretical and practical traditions, contributing to a fuller understanding of the non-sensual forces prevalent in contemporary art.

Rosch, Eleanor, Evan T. Thompson, and Francisco J. Varela. The Embodied Mind: Cognitive Science and Human Experience. London: The Mit Press, 1992.

The Roe's Room. Dir. Lech Majewski. Perf. Rafat Olbrychski, Mieczysław Czepulonis, Elżbieta Mazur, Agnieszka Wroblewska, Artur Stefanowicz. 1994. DVD. Kino on Video, 2008.

The Sacrifice. Dir. Andrei Tarkovsky. Perf. Erland Josephson, Susan Fleetwood, Allan Edwall, Gudrún Gisladóttir, Sven Wollter. 1986. DVD. Kino Video, 2004.

Saussure, Ferdinand de. Course in General Linguistics. In "Contemporary Literary Criticism: Literary and Cultural Studies.” Eds. Con Davis, Robert, and Ronald Schleifer. New York: Longman: 1994.

Scruton, Roger. An Intelligent Person's Guide to Modern Culture. South Bend: St. Augustine's Press, 2000.

This highly intellectual book by Scruton does not hide its bias for high culture as the saviour of human culture. Despite its somewhat controversial content, it offers an open-minded reader a chance to reflect on the cultural constructs of our society.

Segal, Robert A.. Myth: A Very Short Introduction. New York: Oxford University Press, USA, 2004.

Smith, Steven B. "Ideology and Interpretation: The Case of Althusser." Poetics Today. 10.3 (1989): 493-510. 
Solyaris. Dir. Andrei Tarkovsky. Perf. Natalya Bondarchuk, Donatas Banionis, Jüri Järvet. 1972. DVD. Criterion, 2002.

Sontag, Susan. Against Interpretation: And Other Essays. New York, NY: Picador, 2001. The classic Against Interpretation' is a delight to read as Sontag presents a careful analysis of the forces behind purely aesthetic interpretations of art and suggests an approach focused on a much deeper, expanded sensory experience.

Stalker. Dir. Andrei Tarkovsky. Perf. Aleksandr Kajdanovsky, Alisa Frejndlikh, Anatoli Solonitsyn. 1979. DVD. Image Entertainment, 2006.

Stomma, Ludwik. Antropologia Kultury Wsi PolskiejXIX Wieku. Łódź: Dopierała, 2002. Classic anthropological siudy of the XIX century peasant culture of Poland. Stomma's methodology is grounded in historical and mythological discourses, giving an engaging view of the forces shaping the ethos of Polish culture.

Sturm, Brian W. "Storytelling Trance Experience." The lournal of American Folklore 113.449 (2000): 287-304.

An interesting study depicting the relationship between the act of storytelling/listening and trance.

Sulima, Roch. Glosy tradycji. Warszawa: DiG, 2001.

A fascinating critical analysis focused on the social and historical significance of the term "tradition" often misused as a product of consumerism by the contemporary culture of mass media. Sulima retraces the authenticity of Polish tradition by unveiling the many subtleties of its social convictions.

Swanger, David. "Ideology and Aesthetic Education Ideology and Aesthetic Education." Journal of Aesthetic Education. 15.2 (1981): 33-44.

An engaging discussion about the relationship between art and ideology in the pedagogical context.

The Thin Red Line. Dir. Terrence Malick. Perf. Sean Penn, Adrien Brody. James Caviezel, Elias Koteas, and Nick Nolte. 1998. DVD. 20th Century Fox, 1999. A poetic and philosophical journey based on the tenets of Buddhism and Jungian philosophy, exploring man's disenchantment amidst the horrors of war and inner struggle. Marketed as a Hollywood war drama, this art film is a non-linear, multisensory meditation on human interiority. This film ignited my interested in pursuing exploring sacred notions through artistic expression. 
Tolstoy, Leo. What Is Art?. London: Penguin Classics, 1996.

This book presents Tolstoy's argumentation for a higher meaning of art, transcending the established elitist idea of art as a representation of beauty. He posits that art must instigate a form of communication, where the audience becomes "infected" with the sincere message contained in the artistic expression and therefore is unified with the artwork and other viewers, to fully comprehend the embedded meaning. Tolstoy argues that peasant art has the highest amount of "sincerity," and "infectiousness."

Wartofsky, Marx W. "Art, Artworlds, and Ideology." The Journal of Aesthetics and Art Criticism. 38.3 (1980): 239-247.

Welch, John. Spiritual Pilgrims: Carl lung and Teresa of Avila. New York: Paulist Press, 1982.

A fascinating illustration of Jungian philosophy juxtaposed with the symbolism of Christian mysticism. Focused around the notion of human interiority, this books also servers as a great introduction to basic Jungian symbolism.

Williams, Raymond. Culture and Society 1780-1950. Columbia: Columbia University Press, 1983.

-. 'Mass Communication' And 'Minority Culture'. In "Media Studies: A Reader - 2nd Edition." Eds. Marris, Paul, and Sue Thornham. London: NYU Press, 2000. Williams' cultural commentary provides means of understanding contemporary means of communication in the context of culture. Largely concerned with the relationship between culture and ideology, he points out how culture normalizes ideological notions. Furthermore, it is Williams' assertion that meaning is actualized by description through communication, further emphasizing the reciprocity of a communicative act.

Vozvrashcheniye. Dir. Andrei Zvyagintsev. Perf. Vladimir Garin, Ivan Dobronravov, Konstantin Lavronenko. 2003. DVD. Kino International, 2004. 